\title{
Integrated Simulation Framework for Assessing Turbocharger Fault Effects on Diesel Engine Performance and Operability
}

\author{
Konstantinos Ntonas ${ }^{1}$; Nikolaos Aretakis ${ }^{2}$; Ioannis Roumeliotis ${ }^{3}$; \\ Efthimios Pariotis ${ }^{4}$; Yiannis Paraskevopoulos ${ }^{5}$ and Theodoros Zannis ${ }^{6}$
}

Abstract: Turbocharged diesel engines are extensively used in marine vessels, both as propulsion engines and as generator sets. The engines operation in the hostile marine environment results to performance degradation having a negative effect on the economics of the marine vessel's operation both in terms of fuel consumption and maintenance. This paper presents a turbocharged 4-stroke diesel engine simulation framework based on one-dimensional calculations and analysis. The framework is suitable for turbomachinery and heat exchanger components fault simulation predicting both turbocharger and diesel engine performance and operability. Meanline models were used in conjunction with beta lines method for generating accurate and detailed compressor and turbine performance maps, coupled with a single zone closed-cycle diesel engine model for generating engine performance characteristics. The simulation framework modules are adjusted and validated against measured data. Following specific faults are simulated utilizing physical consistent parameters such as blade friction and thickness based on relevant literature data. Overall system simulation and operation analysis is carried out assessing operability and performance parameters. Analysis results show a significant reduction in engine performance, especially in case of both turbo-components being fouled (22\% power reduction), in contrast with the heat exchanger fouling where the power reduction is about $1 \%$.

Author keywords: Turbocharger; Diesel Engine; Centrifugal Compressor; Radial Turbine;

23 Turbocharger fault effects;

$24{ }^{1}$ Research Assistant, Laboratory of Thermal Turbomachines, School of Mechanical Engineering, National Technical University of Athens. Email: kntonas@central.ntua.gr (corresponding author) 
$26{ }^{2}$ Assistant Professor, Laboratory of Thermal Turbomachines, School of Mechanical Engineering, National Technical University

27 of Athens. Email: naret@central.ntua.gr

$28{ }^{3}$ Assistant Professor, Section of Naval Architecture \& Marine Engineering, Hellenic Naval Academy, Piraeus Greece, also

29 Lecturer at Cranfield University. Email: I.Roumeliotis@ cranfield.ac.uk

$30 \quad{ }^{4}$ Assistant Professor, Section of Naval Architecture \& Marine Engineering, Hellenic Naval Academy. Email:

31 pariotis@snd.edu.gr

$32 \quad{ }^{5}$ Founder-Technical Director of Turbomed SA Email: turbomed@otenet.gr

$33{ }^{6}$ Assistant Professor, Section of Naval Architecture \& Marine Engineering, Hellenic Naval Academy. Email:

34 thzannis@snd.edu.gr

35

36

\section{Notation}

\begin{tabular}{|c|c|c|c|c|c|}
\hline AL0 & $=$ & $\begin{array}{l}\text { Compressor diffuser outlet angle, Turbine } \\
\text { nozzle inlet angle. }\end{array}$ & $Q_{\text {comb }}$ & $=$ & $\begin{array}{l}\text { In-cylinder fuel combustion } \\
\text { energy input }\end{array}$ \\
\hline AL1 & $=$ & $\begin{array}{l}\text { Compressor diffuser inlet angle, Turbine } \\
\text { nozzle outlet angle. }\end{array}$ & $Q_{\text {comb,tot }}$ & $=$ & Total heat of combustion \\
\hline ALR3 & $=$ & $\begin{array}{l}\text { Compressor impeller exit sweep angle, } \\
\text { Turbine impeller inlet angle }\end{array}$ & $\mathrm{Qw}_{\mathrm{w}}$ & $=$ & $\begin{array}{l}\text { Heat transfer through the } \\
\text { boundaries of the engine cylinder }\end{array}$ \\
\hline B4 & $=$ & $\begin{array}{l}\text { Compressor impeller inlet angle, Turbine } \\
\text { impeller exit angle }\end{array}$ & $\mathrm{R}$ & $=$ & Resistance \\
\hline $\mathrm{CC}$ & $=$ & Centrifugal Compressor & R0 & $=$ & $\begin{array}{l}\text { Compressor diffuser outlet radius, } \\
\text { Turbine nozzle inlet radius }\end{array}$ \\
\hline C.P, C.T & $=$ & Charged Air Pressure and Temperature & $\mathrm{R} 1$ & $=$ & $\begin{array}{l}\text { Compressor diffuser inlet radius, } \\
\text { Turbine nozzle outlet radius }\end{array}$ \\
\hline $\mathrm{C}_{\text {piston,mean }}$ & $=$ & Mean piston speed & R3 & $=$ & $\begin{array}{l}\text { Compressor impeller outlet } \\
\text { radius, Turbine impeller inlet } \\
\text { radius }\end{array}$ \\
\hline $\mathrm{dP}$ & $=$ & Pressure Drop & R4 & $=$ & $\begin{array}{l}\text { Compressor impeller inlet radius, } \\
\text { Turbine impeller outlet radius }\end{array}$ \\
\hline HDDI & $=$ & Heavy-Duty Direct Injection & $\operatorname{Re}$ & $=$ & Reynolds number \\
\hline HSO & $=$ & $\begin{array}{l}\text { Compressor diffuser height at outlet radius, } \\
\text { Turbine nozzle height at inlet radius }\end{array}$ & RH & $=$ & Relative Humidity \\
\hline LHV & $=$ & Lower Heating Value of Diesel fuel & RT & $=$ & Radial Turbine \\
\hline $\mathrm{m}_{\mathrm{AIR}}$ & $=$ & Diesel engine inlet air mass flow rate & Sfc & $=$ & Specific fuel consumption \\
\hline $\mathrm{m}_{\mathrm{cor}}$ & & Corrected mass flow $(\dot{m} \sqrt{\theta} / \delta)$ & $\mathrm{T} 4, \mathrm{~T} 5$ & $=$ & $\begin{array}{l}\text { Temperature before and after } \\
\text { Radial Turbine }\end{array}$ \\
\hline $\mathrm{m}_{\mathrm{EXH}}$ & $=$ & Diesel engine exhaust gas mass flow rate & RBDW & $=$ & $\begin{array}{l}\text { Compressor impeller outlet } \\
\text { width, Turbine impeller inlet } \\
\text { width }\end{array}$ \\
\hline $\mathrm{m}_{\text {fuel }}$ & $=$ & Diesel engine fuel mass flow rate & $\mathrm{T} / \mathrm{C}$ & $=$ & Turbocharger \\
\hline
\end{tabular}




\begin{tabular}{|c|c|c|c|c|c|}
\hline $\mathrm{N}$ & $=$ & Diesel engine crankshaft speed, T/C speed & $\mathrm{T}_{\text {cyl }}$ & $=$ & In-cylinder Temperature \\
\hline $\mathrm{n}$ & $=$ & Polytropic exponent & TH1 & $=$ & $\begin{array}{l}\text { Compressor diffuser leading edge } \\
\text { normal thickness, Turbine nozzle } \\
\text { trailing edge normal thickness }\end{array}$ \\
\hline $\mathrm{N}_{\mathrm{c}}$ & $=$ & T/C Corrected speed $(\mathrm{N} / \sqrt{\theta})$ & TH4 & $=$ & $\begin{array}{l}\text { Compressor impeller inlet normal } \\
\text { thickness, Turbine impeller exit } \\
\text { normal thickness }\end{array}$ \\
\hline $\mathrm{N}_{\mathrm{c}, \mathrm{des}}$ & $=$ & T/C Design corrected speed & $\mathrm{T}_{\mathrm{exh}}$ & $=$ & Exhaust gas temperature \\
\hline NRBL & $=$ & Number of impeller full blades & $\mathrm{T}_{\text {IVC }}$ & & $\begin{array}{l}\text { Cylinder gas temperature at inlet } \\
\text { valve closing }\end{array}$ \\
\hline NRSBL & $=$ & Number of impeller splitter blades & $\mathrm{T}_{\mathrm{EVO}}$ & $=$ & $\begin{array}{l}\text { Cylinder gas temperature at } \\
\text { exhaust valve opening }\end{array}$ \\
\hline NSTV & $=$ & Number of stator vanes & $\mathrm{T}_{\mathrm{im}}$ & $=$ & $\begin{array}{l}\text { Temperature at diesel engine inlet } \\
\text { manifold }\end{array}$ \\
\hline$\eta_{\mathrm{vol}}$ & $=$ & Diesel engine volumetric efficiency & $\mathrm{U}$ & $=$ & Overall Heat Transfer Coefficient \\
\hline $\mathrm{P}_{\mathrm{amb}}$ & $=$ & Ambient Pressure & $\mathrm{U}_{\text {cyl }}$ & $=$ & $\begin{array}{l}\text { Internal Energy of the engine } \\
\text { cylinder content }\end{array}$ \\
\hline $\mathrm{p}_{\text {cyl }}$ & $=$ & In-cylinder pressure & $\mathrm{V}_{\mathrm{SW}}$ & $=$ & $\begin{array}{l}\text { Diesel engine Cylinder swept } \\
\text { volume }\end{array}$ \\
\hline $\mathrm{P}_{\mathrm{EVO}}$ & $=$ & $\begin{array}{l}\text { Cylinder gas pressure at exhaust valve } \\
\text { opening }\end{array}$ & $\mathrm{W}$ & $=$ & Engine work output \\
\hline $\mathrm{P}_{\text {exh,manif }}$ & $=$ & Gas pressure at exhaust manifold & $\Delta \varphi_{\mathrm{c}}$ & $=$ & $\begin{array}{l}\text { Duration of combustion (in CA } \\
\text { degs) }\end{array}$ \\
\hline $\mathrm{P}_{\mathrm{im}}$ & $=$ & Pressure at diesel engine inlet manifold & $\varepsilon$ & $=$ & Effectiveness \\
\hline $\operatorname{Pr}$ & $=$ & Prandlt number & & & \\
\hline
\end{tabular}

\section{Introduction}

39 Turbocharged diesel engines have been widely used in vehicles, heavy duty trucks, ships, non-

40 interconnected electric power systems and other energy applications. Specifically, they have a leading

41 role in marine industry, used mainly as main propulsion engines and as auxiliary power generator sets

42 (GENSETs). Naval vessels up to frigate class utilize four-stroke diesel engines for propulsion as well as

43 GENSETs since they offer lower acquisition cost, better fuel economy and better response to load

44 changes compared to gas turbines (Bricknell, 2006).

45 As discussed by Button et al. (2015), the bigger contributors in the life cycle cost of the turbocharged 46 diesel engines are maintenance and operational costs. The development of an integrated simulation 47 framework for simulating fault effects on turbocharged diesel engines is expected to contribute towards 
quantifying the degradation effect on operational cost by providing information on the increased fuel consumption and decreased load (Murphy et al., 2015). At the same time, it may provide information on maintenance cost and operability concerning compressor surge margin reduction along with temperature and rotational speed changes that affect bearings life. Additionally, it can be used for providing suitable fault signatures, as discussed by Pagán Rubio et al. (2018).

Turbocharger (T/C) consists of two components, a Centrifugal Compressor (CC) and a Radial (RT) or Axial Turbine depending on diesel engine size. The impact of turbocharger modeling on diesel engine combustion mechanism and performance characteristics have been thoroughly examined in the past by Giakoumis and Tziolas (2018) and by Giakoumis et al. (2017). Also the influence of turbocharger heat transfer modeling both for diesel and gasolines engine performance parameters have been investigated using neural networks by Huang et al. (2018). At present, the design and modeling of both T/C components can be performed by using 1D and 3D analysis. 1D analysis is used to calculate components performance maps using basic geometrical parameters and not the whole geometry in contrast to 3D analysis. Thus, it can be a powerful tool during preliminary design and modeling. In 1D analysis the flow through the impeller is assumed uniform and the off-design performance is calculated using mean streamline single zone models (Galvas 1973, Aungier 1995, Wasserbauer and Glassman 1975). A significant aspect for the compressor map is the prediction of surge line. Rodgers (1963) set the surge and choke limits for a wide range of centrifugal compressors using experimental data. Another approach was made by Japikse (1996), who assumed that a jet-wake structure exists in the impeller passage. Stuart et al. (2017) made a new approach in CC 1D analysis using a three-zone model assuming that impeller exit recirculation influences compressor work input. For the turbine performance, 1D models have been extensively applied, as for example described by Romagnoli and Martinez-Botas (2011) utilizing mean line analysis method well described in the past (e.g. Wasserbauer and Glassman 1975). Applying 1D models for $\mathrm{T} / \mathrm{C}$ component faults simulation and map prediction allows for assessing the fault effect using physical consistent parameters such as roughness increase rather than arbitrary mass flow and efficiency reduction factors used in the literature (Pagán Rubio et al. 2018) providing information, at the same time, of the fault effect on the surge line. 
Studies conducted in the past have examined the effect of various faulty conditions on marine diesel

engine performance characteristics. Specifically, Kökkülünk et al. (2016) investigated the performance degradation of a marine diesel engine by using curve-based approach and Kowalski (2015) developed a methodology of a multidimensional diagnostic tool based on exhaust gas composition of marine engines. Also, Sakellaridis et al. (2015) proposed a turbocharger simulation methodology for marine two-stroke diesel engine modeling and diagnostic applications.

The 3D model provides a high-fidelity analysis, based on CFD simulation and as a time, consuming method, it is used in most cases, as a designing and stability analysis tool. It is also combined with 1D model, for loss correlations adaptation. Japikse and Baines (1997) suggested a turbomachinery component design procedure, combining 1D and 3D model, a procedure followed by Qiu et al (2013), in T/C components design.

The importance of the turbomachinery component maps used as part of a turbocharged engine model has been highlighted by Pesiridis et al. (2012). As discussed, suitable fitting and extrapolation methods should be applied for accurately predicting the engine performance.

In the present work the well-established beta lines method suggested by Kurzke (1996) is applied for ensuring accurate interpolation and extrapolation both for compressor and turbine performance maps generated by corresponding meanline models, described in next section. Various types of models have been proposed and used in the literature for the simulation of performance and emissions of turbocharged diesel engines, depending on the application and configuration examined (Watson and Janota, 1982). Three are the main categories of diesel engine models: zero-dimensional thermodynamic models, quasidimensional phenomenological models and multi-dimensional CFD models. In zero-dimensional thermodynamic models (Baldi et al. 2015 and Catania et al. 2011) the heat release is simulated in a simplified way, using empirical / mathematical expressions, without detailed study of physical and chemical sub-processes that actually take place in the combustion chamber, because these are strongly dependent on the spatial distribution of temperature and composition which are not taken into account. This approach is advantageous in applications where limited data are available regarding the design configuration and the operating parameters of the engine, while computational power is limited, and 
computational time is a critical parameter. In the field of phenomenological simulation models, quite

103 important are the multi-zone combustion models, which provide a temporal and spatial distribution of 104 combustion temperature and mixture composition based on the concept of fuel jet distribution into zones.

105 A fair compromise between more detailed multi-zone and single-zone combustion models is provided by 106 two-zone combustion models, which offer reasonable accuracy at economic computer runtime 107 (Rakopoulos et al., 2003). Two-zone models have been used very effectively for examining the effect of 108 exhaust gas recirculation (EGR) rate and temperature on diesel engine combustion characteristics and 109 pollutant emissions as demonstrated by Rakopoulos et al. (2018). Phenomenological models along with 110 experimental campaigns have been used by Rakopoulos et al. (2015) and Rakopoulos et al. (2019) to 111 examine the effect of various alternative fuels on HDDI turbocharged diesel engine performance 112 characteristics and pollutant emissions under both steady-state and transient conditions. and Liang et al. 2010) are based on locally resolved solution of conservation of mass, energy and

115 momentum and include detailed sub-models for spray and combustion phenomena. With this approach it 116 is possible to obtain detailed results regarding the gas flow pattern and the spatial distribution of 117 temperature and composition inside the combustion chamber. However, these models are very demanding 118 in terms of detailed design data, computational power and expertise to be applied making its use 119 appropriate only for specific applications.

120 The intermediate category is the quasi-dimensional phenomenological models, which allows to 121 execute efficient, fast and economic preliminary calculations of heat release models and exhaust 122 emissions as a function of important engine parameters like injection pressure, injection timing, swirl 123 ratio and boost pressure. These models are based on physical and chemical sub-models for fuel spray 124 formation, air fuel mixing, combustion and emission formation, offering a fair compromise between the 125 detailed CFD ones and the zero-dimensional models, being appropriate as predictive tools conducting 126 parametric studies during engine development (Pagán Rubio et al. 2018, Pariotis and Hountalas 2003 and 127 2004, Pariotis et al. 2005). 
Focusing on models applied to investigate the matching between diesel engine and a turbocharger

129 system, Charlton (1992) proposed the SPICE modeling software, which is a quasi-dimensional model,

130 based on the filling and emptying method and is particularly suited for turbocharged diesel engine

131 systems. The system of components is modeled as a combination of thermodynamic volumes, flow

132 junctions and shafts. The intake and exhaust valves are represented by junctions, each having a schedule

133 of effective flow area versus crankshaft position. One dimensional compressible flow equations are used

134 to obtain flow rates for given pressures in the neighboring volumes. The performance of the turbocharger

135 compressor and turbine is represented by tabulated data taken from performance maps published by the

136 manufacturers.

137 An alternative approach has been proposed by Ledger et al. (1971 and 1973), focusing on the 138 transient simulation of turbocharged engines, by linking steady speed experimental data (regarding engine 139 performance and gas flow) with dynamic models of the mechanical components of the system. However, 140 the weakness of this approach is that it is heavily dependent on experimental data and it oversimplifies the 141 simulation of combustion. A more comprehensive transient model (extended from the filling and 142 emptying model) was developed by Watson and Marzouk (1977). Their model was used to investigate 143 turbocharger response problems at a fundamental level. It takes into account the non-linear influence of 144 combustion on the torque developed and the exhaust-gas energy available at the turbine, the pulsating 145 nature of gas flow (including reverse flow) and also the influence of manifold pressure on pumping work.

The increasing need for marine engine system downsizing, combined with the harsh working conditions, leads to frequent engine components failure, especially for the turbocharger. In order to ensure ship safety operation, by preventing those failures, a fault diagnosis system must be used. For turbocharger fault diagnosis, slight improvement has been made, comparing with the rest of turbomachines (e.g. turbofan, gas turbine, etc.), relying in most cases on engineers' personal experience.

151 At present, Barelli et al. (2009) presented a turbocharger diagnosis methodology based on Artificial 152 Neural Network (ANN) and proposed a frequent data gathering campaign every 6 to 9 months in order to ensure the proper operation of such a system. Sakellaridis and Hountalas (2013) also developed a radial 
measured data. Cui et al. (2018) developed a gas-path diagnosis for diesel engine turbochargers, using health factors (flow capacity and isentropic efficiency), hence monitoring the T/C health status.

The present study proposes a turbocharged diesel engine modeling framework using 1D modeling for $\mathrm{T} / \mathrm{C}$ components, single zone modeling for the diesel engine and matching analysis between $\mathrm{T} / \mathrm{C}$ and diesel engine. The diesel engine model is adapted to engine specific data and the overall integrated model is validated against shop trials data obtained from a marine diesel generator. Having developed a model capable to simulate the system operation over its whole envelope, engine fouling analysis is performed in order to determine how fouling in $\mathrm{T} / \mathrm{C}$ and intercooler affects the whole system operation.

The T/C component faults simulation is materialized using physical consistent parameters such as roughness increase rather than arbitrary mass flow and efficiency reduction factors (Kurz and Brun 2009) or time consuming CFD analysis (Melino et al. 2011) used in the literature. In this way the fault effect on the surge line is provided, thus the effect of faults on operability, usually neglected in the literature, is assessed as well.

\section{Integrated Simulation Platform}

The integrated simulation platform utilizes 1D models for calculating the T/C component maps based on the available geometry, then a fully coupled process integrating the T/C components the diesel engine and the intercooler is applied for calculating the performance and operating conditions at sub-system and system level.

\section{Turbocharger Modeling}

The turbocharger can be modeled by using specific compressor and turbine maps, a feature that can be applied when measured maps are available or when the geometry of the turbocharger is not available. In the latter case appropriate scaled maps can be used. In the case that measured turbomachinery geometry is available or the simulation system is used as part of an integrated pre-design or/and optimization procedure, or specific faults are to be simulated, suitable mean line aerothermodynamic models are used for calculating the component maps. A hybrid modeling approach can also be applied, for example using a measured map for the compressor and a map calculated based on geometry for the turbine. 
For simulating Variable Geometry, either in the case of Inlet Guide Vanes for the compressor and

183 Variable Guide Vanes for the turbine the simulation tool can handle multimaps performing 3-D 184 interpolations as discussed by Alexiou et al. (2012). If the meanline codes are applied for the T/C 185 components modeling then the Variable Geometry is integrated to the calculations, since the maps are

191 ratio and efficiency for different corrected rotational speeds an in-house compressor meanline code is 192 used. The 1-D code is based on the methodology presented in (Galvas, 1973). The flow properties are 193 calculated along a streamline in mean radial position using Wiesner slip factor. The compressor 194 performance is evaluated using empirical correlations for compressor losses and flow deviation. The 195 meanline program allows the calculation of the compressor map without increasing the time for the 196 overall matching of the integrated system. Additionally, compressor geometry optimization can be 197 performed not in isolation but in the frame of an integrated system. The geometry related inputs of the 198 compressor code can be seen in Fig. 1.

The meanline code has been validated against experimental data published by NASA-Galvas (1973). As seen in Fig.2 and Fig. 3 the map derived for the specific geometry is in good agreement with the experimental data, especially for rotational speeds lower than the maximum one. The deviation between the experimental and calculated data increases as rotational speed increases, since at high rotational speeds the 3-D phenomena become significant. This error trend is similar to the original code presented by Galvas (1973). For surge line prediction, two surge criteria are taken into account, namely one for impeller inducer and one for vaned diffuser surge. Both surge limits are calculated with empirical correlations, developed by Rodgers (1963) and Galvas (1973) respectively. 
Similar to the compressor, a meanline code based on the work of Wasserbauer et al. (1975) is used.

209 In this meanline model, the flow properties are calculated along a streamline in mean radial position,

210 computing turbine performance using empirical correlations for radial turbine losses and angle deviation.

211 The geometry related inputs of the turbine code can be seen in Fig. 4. The code is validated against 212 measured data for a specific geometry (Wasserbauer and Glassman, 1975). The results indicate that both 213 chocking line and low pressure operating region are predicted with good accuracy, as seen in Fig. 5

\section{Diesel Engine Model}

For diesel engine modeling an in-house single zone thermodynamic combustion model has been used for the closed engine cycle. The main scope of the simulation model developed is to predict the engine performance, the thermodynamic properties of the working medium and its mass flow rate, in order to be coupled with the compressor and turbine model, using as little as possible experimental data for model calibration. Therefore, a simple approach is followed, which is based on the application of the first law of thermodynamics assuming that the entire combustion chamber consists of a single homogeneous mixed charge. Thus, only the temporal variation of the in-cylinder mixture concentration, temperature and thermodynamic properties is considered, as a function of the instantaneous cylinder volume. In other words, at each crank angle degree integration step, the model predicts the in-cylinder homogeneous mixture composition (i.e. perfect combustion products concentrations after combustion initiation), the incylinder pressure and the uniform in-cylinder bulk gas temperature. For the close part of engine cycle the energy conservation equation is written as:

$$
\frac{d U_{c y l}}{d t}=\frac{d Q_{w}}{d t}+\frac{d Q_{c o m b}}{d t}-\frac{d W}{d t}
$$

The mechanical work performed by the piston during the compression and expansion phase is due to the volume change of the cylinder and is calculated by the following trapezoidal rule:

$$
d W=\left(p_{c y l, i}+p_{c y l, i+1}\right) * \frac{d V_{c y l}}{2}
$$


where $p_{c y l, i}$ and $p_{c y l, i+1}$ are two successive values of cylinder pressure and $d_{\text {cyl }}$ is the cylinder

230 volume step.

The heat addition via combustion is taken into account assuming complete combustion of the fuel injected with a specified lower heating value. The fuel burning rate at each crank angle degrees, is predetermined using a simple empirical model (Wiebe function) according to the following expression (Stiesch, 2003)

$$
\frac{Q_{c o m b}(\varphi)}{Q_{c o m b, t o t}}=1-\exp \left(-6.908 *\left(\frac{\varphi-\varphi_{S o C}}{\Delta \varphi_{c}}\right)^{m+1}\right)
$$

Where $Q_{c o m b, t o t}=m_{f u e l} * L H V, \mathrm{~m}$ and $\Delta \varphi_{c}$ are parameters determined through the calibration procedure conducted. The ignition delay is estimated using an Arrhenius type equation (Heywood, 1988):

$$
\tau_{i d}=A * p_{c y l}^{-n} * \exp \left(\frac{E_{A}}{\widetilde{R}} * \frac{1}{T_{c y l}}\right)
$$

237 Where, $\mathrm{P}$ and $\mathrm{T}$ are the instantaneous in-cylinder pressure and temperature, $E_{A}$ is the apparent activation 238 energy of the fuel auto-ignition process, $\tilde{R}$ is the universal gas constant and $\mathrm{A}$ and $\mathrm{n}$ are constants 239 dependent on the fuel. In this study the values proposed by Wolfer are used, i.e. $n=1.19, \mathrm{~A}=0.44$ and the 240 parameter $E_{A} / \tilde{R}=4650 \mathrm{~K}($ Heywood, 1988).

The heat transfer between the cylinder gases and the combustion chamber walls can be due to both convection and solid body radiation which originates from hot soot particles. However, as stated in the model developed the assumption of ideally mixed combustion chamber is made, therefore, soot particles are not taken into account. To compensate this, the effect of radiative heat transfer is taken into account by an empirical augmentation of the convective heat transfer coefficient (Stiesch, 2003). The convective heat transfer rate between the gas and the wall can be described by the Newton's cooling law:

$$
\dot{Q_{w}}=h * A *\left(T_{w}-T_{c y l}\right)
$$

247 Where $\mathrm{h}$ is the convective heat transfer coefficient, $\mathrm{A}$ is the instantaneous surface area of heat transfer and $T_{w}, T_{c y l}$ are the mean wall and in-cylinder gas temperatures respectively. The convective heat transfer 249 coefficient is estimated assuming that an analogy with a steady turbulent flow over a solid wall exists, 250 using the following expression: 


$$
N u=\frac{h * L}{k}=C * R e^{a} * \operatorname{Pr}^{b}
$$

251 Where L represents a characteristic length and equals the cylinder bore diameter, $\mathrm{C}, \mathrm{a}$ and $\mathrm{b}$ are empirical 252 constants that are determined by curve fitting experimental data of wall heat transfer rates. In this study $253 \mathrm{a}=0.80, \mathrm{~b}=0.40$. To calculate the brake engine power, the correlation proposed by Chen and Flynn (1965) 254 for turbocharged engines are used, where the friction mean effective pressure FMEP in bar is calculated 255 as:

$$
F M E P=0.137+0.005 * P_{\text {max }}+0.162 * c_{\text {piston,mean }}
$$

256 Where $\mathrm{P}_{\max }$ is the peak combustion in-cylinder pressure in bar and $\mathrm{c}_{\text {piston,mean }}$ is mean piston speed in $\mathrm{m} / \mathrm{s}$.

257 The air mass flow rate is calculated using the following expression:

$$
\dot{m}_{A I R}=\frac{P_{i m}}{R * T_{i m}} * V_{s w} * n_{v o l} *\left(\frac{N}{2}\right)
$$

258 Where $P_{i m}$ and $T_{i m}$ are the pressure and temperature at the engine inlet manifold (after inter-cooler), $n_{v o l}$ 259 is the volumetric efficiency, $R$ is the air gas constant and $\mathrm{N}$ is the engine crankshaft speed. The gas 260 temperature at IVC is calculated using the following equation:

$$
T_{I V C}=T_{i m}+\Delta T
$$

261 Where $\Delta \mathrm{T}$ is an adjusted input parameter to the integrated simulation model.

The volumetric efficiency $\mathrm{n}_{\mathrm{vol}}$ used in Eq. (8) is adjusted in order predicted data for peak cylinder

263 pressure, brake power output and exhaust gas temperature after turbocharger to match corresponding shop 264 trials data. The exhaust gas flow rate is calculated by:

$$
\dot{m}_{E X H}=\dot{m}_{A I R}+\dot{m}_{f u e l}
$$

265 A polytropic expansion is used to calculate exhaust gas temperature using corresponding value of exhaust 266 gas temperature at EVO as follows:

$$
T_{\text {exh }}=T_{E V O}\left(\frac{P_{\text {exh,manif }}}{P_{E V O}}\right)^{\frac{n-1}{n}}
$$

267 Where $\mathrm{P}_{\mathrm{EVO}}$ is the cylinder gas pressure at EVO and $\mathrm{P}_{\text {exh,manif }}$ is the exhaust manifold pressure, which is 268 calculated using the following expression: 


$$
P_{\text {exh,manif }}=\frac{1}{2} P_{i m}+\sqrt{\left(P_{i m} 100\right)^{2}-8 \dot{m}_{e x h}^{2} T_{i m}+\left(T_{E V O}-T_{i m}\right)}
$$
point are defined according to the following equations (Alexiou and Tsalavoutas, 2013).

$$
\begin{gathered}
\varepsilon=\frac{\mathrm{T}_{\mathrm{in}, \text { hot }}-\mathrm{T}_{\text {out }, \text { hot }}}{\mathrm{T}_{\mathrm{in}, \text { hot }}-\mathrm{T}_{\text {in, cold }}} \\
P_{\text {out,cold or hot }}=P_{\text {in,cold } \text { or hot }}\left(1-d P_{\text {cold or hot }}\right)
\end{gathered}
$$
model. Specifically, the model predicts the variation of in-cylinder pressure during closed-cycle diesel engine operation and thus, it does not account for the variation of cylinder pressure during intake stroke in order to calculate the pumping work during gas exchange. However, the impact of the negative pumping power on the brake engine power output is rather limited since the highest portion of indicated power results from the closed-cycle engine operation and thus, the error induced in the calculation is not considerably important. The results from a more detailed phenomenological model which is under development, considering the time and space evolution of the fuel jet, along with cylinder pressure predictions during gas exchange process, will be presented in a future paper. However, it should be underlined that the main scope of the selection of single-zone approach was based on the fact that it is suitable for cases where there are very limited available data for the geometrical and the operational characteristics of the engine. This is the case that is usually met in practical applications where turbomatching has to be implemented in existing engines under retrofitting (i.e. replacement of existing turbocharger with another one) where the only available data are the test records of the diesel engine at shop trials.

\section{Intercooler}

The intercooler performance is estimated by prescribing the intercooler effectiveness and total pressure losses on the hot and cold sides. The temperature effectiveness $(\varepsilon)$ and pressure drop at design

Where $\mathrm{dP}_{\text {cold }}$ or hot is the pressure drop in the intercooler. In order to estimate the outlet temperatures of both cold and hot side of the intercooler, a heat flow balance is performed between the hot and cold

At this point it is worth to make some observations about the diesel engine closed-cycle simulation 
sides. For off-design operation the pressure drop is a function of mass flow deviating relative to design as

291 is the effectiveness (Walsh and Fletcher, 2008).

\section{Coupling between T/C and Diesel Engine}

$\mathrm{CC}$ and RT geometries are used as input data for the meanline models in order corresponding

294 performance maps to be generated. The input data for diesel model set up are the inlet valve closing

295 angle, the exhaust valve opening angle, the compression ratio, the cylinder bore, the piston stroke, the 296 generator efficiency and the shop trials data. The input data for intercooler model set up are the inlet air 297 mass flow, pressure drop and effectiveness at nominal point (100\% of load). Having established the 298 integrated model for a specific turbocharged diesel engine, the required input data for a single operating 299 point run are ambient conditions, engine speed and engine fuel consumption (or demanded output power).

300 This procedure flow chart is depicted in Fig. 6.

\section{Test Case Engine}

The present integrated simulation platform is used to simulate the operation of a specific turbocharged marine diesel engine throughout its whole operating envelope. The technical specifications of the diesel engine are shown in Table 1.

The results are compared against engine shop trials data for validating the overall system model. The shop trials data are shown in Table 2.

\section{Experimental Verification}

As discussed, the approach followed for the simulation of diesel engine operation is based on empirical and semi-empirical expressions to determine the fuel burning rate, heat transfer and friction power losses. Therefore, it is necessary to calibrate model's constants by comparing the output of the simulation model with corresponding available experimental data. It should be noticed, that since the original scope of the simulation framework was to be used as a tool in retrofitting existing engines, the data used for model calibration are limited to the ones usually found in shop test records, which for the case examined are: engine brake power output, peak in-cylinder combustion pressure and exhaust gas 
temperature. The values of the calibration constants are determined following an optimization procedure

318 to minimize the error when comparing calculated and measured values at each operating point $(25 \%$,

$31950 \%, 75 \%$ and $100 \%$ of full engine load) and at rated engine speed.

In Fig. 7 the comparison between the measured and the calculated values for brake engine power,

321 peak combustion pressure and exhaust gas temperature, at the engine operating conditions used for 322 calibration is depicted. As observed, there is a good matching between measured and calculated values, 323 which indicates that the model reliably reproduce the specific engine operation for the entire range of the 324 conditions examined. It should be noted that one set of calibration parameters is used for the whole 325 operating envelope.

\section{Turbocharged Engine model validation with Engine shop trials}

The geometry of the compressor and turbine has been measured and used as input to the mean line compressor and turbine codes. The specific fuel consumption and boost pressure against engine power is presented in Fig. 8 for five different operating points (Load: 25, 50, 75, 100 and 110\%) as reported in the engine shop trials.

As seen, the integrated turbocharged engine model simulates the overall engine operation in very good agreement to the engine shop trials data. The maximum deviation from the reported mean sfc and boost pressure value is $2.6 \%$ and $9 \%$ respectively. It should be noted that the reported at the shop trials maximum measurement error for the sfc is 5\%. The matching of $\mathrm{T} / \mathrm{C}$ components with engine is presented in Fig. 9 and Fig. 10 where the compressor and turbine maps with corresponding operating lines are shown.

Having established a model that can simulate the turbocharged engine throughout its operating envelope the effect of specific faults on performance and operability can be assessed and the system behavior can be analyzed. Specifically, T/C components and heat exchanger fouling is examined herein.

\section{Turbocharger fouling assessment}

Turbocharger fouling can be caused due to compressor fouling, turbine fouling or a combination of both, leading to inefficient operation and a shift of operating and surge line. All compressors are 
susceptible to fouling as a result of the ingestion of air impurities that accumulate on and stick to gas path

344 free surfaces, blades and shrouds, modifying airfoil geometry (Diakunchak, 1992). In addition, oil leaks

345 from compressor seals and bearings mix with some of the ingested particles and deposit on the blade

346 surfaces (Lakshminarasimha et al. 1994). The result will be the deterioration of airfoils aerodynamic

347 behavior and reduction of flow area leading to the compressor and engine performance degradation.

348 Turbine fouling is mainly depending on type and quality of the operating fuel as discussed by Meher-

349 Homji (1987). When heavy fuel oil or crude oil is used, the turbine degradation is expected to be

350 significant. Low melting point ashes, metals and unburned hydrocarbons can be aggregated in the turbine

351 in the form of scale. The contaminants deposition will have an impact over blade, by changing the airfoil

352 shape, the inlet angle and increasing the surface roughness. These effects will result to the reducing of the

353 airfoil throat area and apparently reducing the performance characteristics and the service life of the 354 component. Also, especially in marine gas turbines, sulfidation may occur resulting in turbine corrosion.

355 As a result, fouling rate will increase, as discussed by Basendwah et al. (2006)

Since both T/C components may be fouled, five different fouling cases are simulated herein. The

simulation is performed by altering the blade thickness and friction accordingly, as presented in Table 3.

The selected blade thickness change due to fouling is between 0.2 and $0.5 \mathrm{~mm}$ as proposed by Mezheritsky and Sudarev(1990) for a medium size T/C.

The results of fouling analysis are shown in Fig11 -Fig13. As seen in Fig. 11, compressor fouling causes the movement of the surge line towards lower pressure ratios for high rotational speeds, hence reducing the compressor stable operation regime. Turbine fouling is mostly affecting the inlet mass flow and turbine efficiency hence reducing shaft horse power and increasing specific fuel consumption. As seen in Fig. 12 the fifth simulated case (F2-F3), which is the most severe one, results to a shaft horse power reduction of $22 \%$ highlighting the effect that $\mathrm{T} / \mathrm{C}$ components fouling can have on a turbocharged engine. For this reason the original nominal power demand canot be satisfied for this case.The effect of fouling on fuel consumption is considerable leading to a specific fuel increase of about $5 \%$ for the worst case, as depicted in Fig. 13. 
For further interpretation of the fouling analysis, additional simulation is performed, with results

370 presented in Table 4 highlighting the effect of fouling in engine performance degradation for constant

371 engine speed and load. The demanded shaft power, used in this simulation, represents the fifth simulated

372 case (F2-F3) maximum power, aiming to ensure that engine operates stable in all fouling conditions. It is

373 observed that as the fouling level increases, the fuel consumption increases in order to satisfy the

374 demanded load. Also boost pressure and T/C rotational speed reduction occurs due to compressor and 375 turbine degradation. Final, the system outlet temperature rises, because of the turbine efficiency 376 reduction.

378 Intercooler fouling assessment

379 The air density determines the maximum weight of fuel that can be effectively burned per working 380 stroke in the cylinder. The increase in air density can be performed by decreasing the charged temperature 381 leading to power increase. The intercooling is used for this purpose. In most cases, intercooler consists of 382 three channels.

$383 \quad \circ \quad$ Air channel

$384 \quad \circ \quad$ Brackish water channel

$385 \quad$ O Sea water channel

386 Brackish water drains heat energy from charged air through a finned tube exchanger, increasing its 387 density. This energy is transferred in next step to sea water through a secondary exchanger. In order to 388 perform the simulation of a fouled intercooler it was assumed that:

○ Maximum fouling sea water resistance is $0.176 \mathrm{~m}^{2} \mathrm{~K} / \mathrm{kW}$ (Kakac et al. 2012)

- Maximum pressure drop increase is $0.29 \%$ due to fouling. (Gautam et al. 2017)

392 effectiveness ratio can be determined as follows. 


$$
\frac{\varepsilon_{\text {clean }}}{\varepsilon_{\text {fouled }}}=\frac{\frac{1}{U_{\text {clean }}}+R_{\mathrm{f}}}{\frac{1}{U_{\text {clean }}}}
$$

Thus, calculating $\varepsilon_{\text {fouled }}$ and using it, in turbocharged engine model, sfc, power and temperature 394 changes can be calculated. Heat exchanger fouling leads to effectiveness reduction and pressure drop 395 increase, hence, the air density before the manifold is decreased causing engine shaft horse power and 396 efficiency reduction. The fuel consumption is increased by $1 \%$ as reported in Table 5, thus heat exchanger 397 fouling economic effect can become significant. In addition exhaust gas temperature increases significant 398 and turbocharger operating line is moved towards surge (Fig. 14), expected to affect turbocharger stable 399 operation.

400 The heat exchanger fouling rate depends on many parameters, including time. It is of interest to assess 401 how the buildup of heat exchange fouling affects the overall turbocharged engine performance over time. 402 The changes of pressure drop and resistance over time are evaluated according to the following and the 403 values discussed, while time is assumed dimensionless, for expressing the relative change of performance 404 parameters over time (see Fig 15 and Fig 16).

$405 \quad \circ$ Pressure drop reduction function against fouling resistance has parabolic form. (Gautam et al. 2017) degradation rate is expected to be reduced over time.

\section{Conclusion}

413 An integrated simulation framework for turbocharged internal combustion engine performance and 414 operability assessment has been developed. For the turbomachinery components 1D models have been 415 applied for analyzing the impact of turbomachinery fouling on sub-system and system level. The effect of 
intercooler fouling has been assessed as well. The assessment is undertaken utilizing models suitable

417 adapted to shop trials data. The results indicate that:

418 Compressor fouling causes the movement of the surge line towards lower pressure ratios, hence

419 reducing the compressor stable operation regime. Turbine fouling is mostly affecting the inlet mass flow and turbine efficiency reducing shaft horse power and increasing specific fuel consumption. As for the combination of compressor and turbine fouling, power may be reduced up to $22 \%$ highlighting the effect that $\mathrm{T} / \mathrm{C}$ components fouling can have on a turbocharged engine and leading to a $5 \%$ specific fuel 423 consumption increase.

Heat exchanger fouling leads to effectiveness reduction and pressure drop increase resulting, for the case examined herein, to $1 \%$ specific fuel consumption increase and $1 \%$ power decrease, indicating that intercooler fouling may affect the engine life cycle cost. In addition exhaust gas temperature increases significant, an increase that is expected to affect the turbocharger bearings life. Also, turbocharger operating line is moved towards surge line, increasing the chance of working under unstable operation.

The present simulation framework has a lot of possible other applications apart from the study of engine system degradation due to fouling in $\mathrm{T} / \mathrm{C}$ components and heat exchanger. It can be an integrated part either of a retrofitting platform with design and optimization modules or of a diagnostic tool, for predictive maintenance purposes. Therefore, the authors intent to replace the single-zone diesel engine model by a more detailed phenomenological one coupled with detailed modeling for NOx emissions from marine diesel engine, while $\mathrm{CO} 2$ emissions will be directly calculated by the fuel consumption.

Finally, the present framework can be used to any type of turbocharged engine after specific modifications, which include adaptation of engine modeling to gasoline or diesel engine geometrical and operational specifications and individual combustion conditions. The single-zone combustion model modifications for gasoline engines include the selection of a Wiebe function suitable for gasoline combustion and the observation of cylinder pressure variation rate for controlling fuel supply to avoid pre-ignition or post-combustion knocking phenomena. Single-zone combustion concept can be considered more suitable for gasoline combustion modeling due to its predominantly premixed nature. 
All the data generated or used during the study are available from the corresponding author by 445 request.

\section{References}

448 Alexiou A., Roumeliotis I., Aretakis N., Tsalavoutas A. and Mathioudakis K. (2012). "Modelling ContraRotating Turbomachinery components for engine performance simulations: The geared turbofan with Contra-Rotating core case". ASME J. Eng. Gas Turbines Power, 134(11): 111701 (10 pages).

Alexiou, A. and Tsalavoutas, A. (2013). Turbo 3.2 Library Reference Manual. Madrid: Empresarios Agrupados Internacional S.A.

Aungier, R.H. (1995). "Mean streamline aerodynamic performance analysis of centrifugal compressor". ASME J. Turbomach, 117(3): 360-366 (7 pages).

Baldi, F., Theotokatos, G, and Andersson, K. (2015). "Development of a combined mean value-zero dimensional model and application for a large marine four-stroke Diesel engine simulation." Applied Energy 154, 402-415. doi:https://doi.org/10.1016/j.apenergy.2015.05.024

Barelli, L., Bidini, G. and Bonucci, F. (2009). "Diagnosis methodology for the turbocharger groups installed on a 1 MW internal combustion engine." Applied Energy 86(12), 2721-2730. https://doi.org/10.1016/j.apenergy.2009.04.034

Basendwah, A., Pilidis, P. and Li, Y.G. (2006). “Turbine Off- Line Water Wash Optimization Approach for Power Generation.” Proceeding of ASME Turbo expo, Barcelona, Spain, 8-11 May, GT200690244, pp. 65-76; 12 pages.

Bricknell, D.J. (2006). "Marine Gas Turbine Propulsion System Application.” Proceeding of ASME Turbo Expo, Barcelona, Spain, 8-11 May, GT2006-90751.

Button, R.W., Martin, B., Sollinger, J. and Tidwell, A. (2015). “Assessment of Surface Ship Maintenance Requirements."

CA: RAND Corporation, https://www.rand.org/pubs/research_reports/RR1155.html. Also available in print form.. 
Catania, A.E., Finesso, R., and Spessa, E. (2011). "Predictive Zero-Dimensional Combustion Model for DI Diesel Engine Feed-Forward Control.” Energy Conv. Manageme. 52(10), 3159-3175. doi:10.1016/j.enconman.2011.05.003

Charlton, S.J. (1992). “SPICE - Simulation program for internal combustion engines.” User Manual (University of Bath).

Chen, S. and Flynn, P. (1965). "Development of a Single Cylinder Compression Ignition Research Engine.” SAE Technical Paper 650733, SAE, Warrendale, PA, pages 14. doi:https://doi.org/10.4271/650733

Cui, X., Yang, C., Serrano, J., and Shi, M. (2018). "A performance degradation evaluation method for a turbocharger in a diesel engine." $R$. Soc. Open Sci. 5: 181093. doi:http://dx.doi.org/10.1098/rsos.181093

Diakunchak, I. S. (1992). "Performance Deterioration in Industrial Gas Turbines." ASME J. Eng. Gas Turbines Power, 114(2): 161-168 (8 pages).

Galvas, M.R. (1973). "Fortran program For predicting off design performance of Centrifugal Compressor." NASA TN D-7487.

Giakoumis, E.G., Dimaratos, A.M., Rakopoulos, C.D., and Rakopoulos, D.C. (2017) “Combustion instability during starting of turbocharged diesel engine including biofuel effects", J. Energy Engineering, ASCE, 143(2), 04016047. DOI: 10.1061/(ASCE)EY.1943-7897.0000402

Giakoumis, E.G., and Tziolas, V. (2018) "Modeling a variable-geometry turbocharged diesel engine under steady-state and transient conditions", J. Energy Engineering, ASCE, 144(3), 04018017, DOI: 10.1061/(ASCE)EY.1943-7897.0000537.

Guatam, K-R., Parmar, N., and Vyas, B. (2017) "Effect of fouling on thermal and hydraulic parameter of Shell and Tube Heat exchanger", Student conference 2017, Czech Technical University, At Prague, Czech Republic

Heywood, J. B. (1988). Internal combustion engine fundamentals. McGraw-Hill, New York. 
Huang, L., Ma, C., Li, Y., Gao, J., and Qi, M. (2018) “Applying neural networks (NN) to the improvement of gasoline turbocharger heat transfer modeling”, Applied Thermal Engineering, 141, 1080-1091, https://doi.org/10.1016/j.applthermaleng.2018.06.062.

Japikse, D. (1996). Centrifugal Compressor Design and Performane. 3rd ed., Concepts ETI Inc.: Wilder,TN, USA, pp. 2.26-2.81.

Japikse, D., and Baines, N.C. (1997). Introduction to Turbomachinery. Concepts ETI Inc and Oxford University Press.

Kakac, S., Liu, H., and Pramuanjaroenkij, A. (2012). Heat Exchangers. CRC Press.

Kökkülünk, G., Parlak, A., and Erdem, H-H. (2016) "Determination of performance degradation of a marine diesel engine by using curve based approach", Applied Thermal Engineering, 108, 11361146, http://dx.doi.org/10.1016/j.applthermaleng.2016.08.019.

Kowalski, J. (2015) "Concept of the multidimensional diagnostic tool based on exhaust gas composition for marine engines", Applied Energy 150, 1-8. https://doi.org/10.1016/j.apenergy.2015.04.013

Kurz, R., and Brun, K. (2009). "Degradation of gas turbine performance in natural gas service." Journal of Natural Gas Science and Engineering, 1, 95-102. doi:10.1016/j.jngse.2009.03.007

Kurzke, J. (1996). "How to get Component Maps for Aircraft Gas Turbine Performance Calculations." Proceeding of ASME Turbo Expo, Birmingham, UK, 96-GT-164, 2-5 June, 7 pages

Lakshminarasimha, A.N., Boyce, M.P., and Meher-Homji, C.P. (1994). "Modelling and Analysis of Gas Turbine Performance Detrerioration.” ASME J. Eng. Gas Turbines Power, 116(1), 46-52. https://doi.org/10.1115/1.2906808

Ledger, J.D., Benson, R.S., and Furukawa, H. (1973). "Improvements in transient performance of a turbocharged diesel engine by air injection into the compressor." SAE Paper No. 730665, SAE, Warrendale, PA. https://doi.org/10.4271/730665.

Ledger, J.D., and Walmsley, N.D. (1971). "Computer simulation of a turbocharged diesel engine operating under transient load conditions." SAE Paper No. 710117, SAE, Warrendale, PA.

Liang, L., Naik, C., Puduppakkam, K., Wang, C., Modak, A., Meek, E., Ge, H., Reitz, R., and Rutland, C. (2010). "Efficient Simulation of Diesel Engine Combustion Using Realistic Chemical Kinetics 
in CFD.” SAE Paper No. 2010-01-0178, SAE, Warrendale, PA doi:https://doi.org/10.4271/201001-0178

Meher-Homji, C.B . (1987). "Compressor and Hot Section Fouling in Gas Turbines - Causes and Effects." Proceedings of the $9^{\text {th }}$ Industrial Energy Technology Conference. Houston: Texas A\&M University.

Melino, M., Morini, M., Peretto, A., Pinelli, M., and Spina, P.R. (2011). “Compressor Fouling Modeling: Relationship Between Computational Roughness and Gas Turbine Operation Time.” Proceeding of ASME Turbo Expo, Vancouver, British Columbia, 6-10 June.

Mezheritsky, A.D., and Sudarev, A.V. (1990). "The mechanism of fouling and the cleaning technique in application to flow parts of the power generation plant compressors." Proceeding of ASME Turbo Expo, Brussels, Belgium, 90-GT-103, 11-14 June.

Murphy A.J., Norman, A.J., Pazouki, K., and Trodden, D.G. (2015). "Thermodynamic simulation for the investigation of marine Diesel engines." Ocean Engineering, 102, 117-128. https://doi.org/10.1016/j.oceaneng.2015.04.004

Pagán Rubio, J.A., Vera-García, F., Hernandez Grau, J., Muñoz Cámara, J., and Albaladejo Hernandez, D. (2018). "Marine diesel engine failure simulator based on thermodynamic model." Applied Thermal Engineering., 144, 982-995. doi:https://doi.org/10.1016/j.applthermaleng.2018.08.096

Pariotis, E. and Hountalas, D. (2003). “A New Quasi-Three Dimensional Combustion Model for Prediction of DI Diesel Engines' Performance and Pollutant Emissions.” SAE Transactions, J. Engines, 112, 1417-1429 . doi:https://doi.org/10.4271/2003-01-1060

Pariotis, E. and Hountalas, D. (2004). "Validation of a Newly Developed Quasi-Dimensional Combustion Model - Application on a Heavy Duty DI Diesel Engine.” SAE Paper 2004-01-0923, SAE, Warrendale, PA, Pages 15. doi:https://doi.org/10.4271/2004-01-0923

Pariotis, E., Hountalas, D., and Rakopoulos, C. (2005). "Modeling the Effects of EGR on a Heavy Duty DI Diesel Engine Using a new Quasi-Dimensional Combustion Model.” SAE Paper 2005-011125, SAE, Warrendale, PA, Pages 20. https://doi.org/10.4271/2005-01-1125 
Pesiridis A., Salim, W., and Martinez-Botas, R.F. (2012). Turbocharger Matching Methodology for

Qiu, X., Fredriksson, C.F., Baines, N.C., and Backlund, M. (2013). "Designing turbochargers with an integrated design system." Proceedings of ASME Turbo Expo, San Antonio, Texas, USA, 3-7 June, GT2013-94894.

Rakopoulos, C.D., Rakopoulos, D.C., and Giakoumis, E.G. (2015). "Impact of properties of vegetable oil, bio-diesel, ethanol and n-butanol on the combustion and emissions of turbocharged HDDI diesel engine operating under steady and transient conditions." Fuel 156, 1-19. https://doi.org/10.1016/j.fuel.2015.04.021

Rakopoulos, C.D., Rakopoulos, D.C., Kosmadakis, G.M., and Papagiannakis, R.G. (2019). "Experimental comparative assessment of butanol or ethanol diesel-fuel extenders impact on combustion features, cyclic irregularity, and regulated emissions balance in heavy-duty diesel engine." Energy 174, 1145-1157. https://doi.org/10.1016/j.energy.2019.03.063

Rakopoulos, C.D., Rakopoulos, D.C., and Kyritsis, D.C. (2003). "Development and validation of a comprehensive two-zone model for combustion and emissions formation in a DI diesel engine." Int. J. Energy Res. 27(14), 1221-1249. https://doi.org/10.1002/er.939

Rakopoulos, C.D., Rakopoulos, D.C., Mavropoulos, G.C., and Kosmadakis, G.M. (2018). "Investigating the EGR rate and temperature impact on diesel engine combustion and emissions under various injection timings and loads by comprehensive two-zone modeling." Energy 157, 990-1014. https://doi.org/10.1016/j.energy.2018.05.178

Reitz, R.D., and Rutland, C.J. (1995). "Development and testing of diesel engine CFD models." Progress in Energy and Combustion Science, 21, 173-196. doi:https://doi.org/10.1016/0360$1285(95) 00003-Z$ 
Rodgers, C. (1963). "Typical Performance Characteristics of Gas Turbine Radial Compressors.” ASME J. Eng. Power. Apr 1964, 86(2): 161-170 (10 pages).

Romagnoli, A. and Martinez-Botas, R. (2011). "Performance Prediction of a Nozzled and Nozzleless Mixed-flow.” Int. J. Mechanical Sciences, 53(8):557-574.

Sakellaridis, N. and Hountalas, D. (2013). "Meanline Modeling of Radial Turbine Performance for Turbocharger Simulation and Diagnostic Applications.”, SAE Technical Paper 2013-01-0924, SAE, Warrendale, PA, Pages 13. doi:https://doi.org/10.4271/2013-01-0924

Sakellaridis, N.F., Raptotasios, S.I., Antonopoulos, A.K., Mavropoulos, G.C. and Hountalas, D.T. (2015) "Development and validation of a new turbocharger simulation methodology for marine two stroke diesel engine modelling and diagnostic applications", Energy, 91, 952-966, http://dx.doi.org/10.1016/j.energy.2015.08.049

Stiesch, G. (2003). Modeling Engine Spray and Combustion Processes. Heat and Mass Transfer. Springer Berlin Heidelberg, Berlin, Heidelberg.

Stuart S., Spence S., Filsinger D., Starke A., Kim S. K. (2017). "Characterising the influence of impeller exti recirculation on Centrifugal Compressor work input." Proceeding of ASME Turbo Expo, Charlotte, NC, USA, 26-30 June, GT2017-63047.

Walsh, P.P. and Fletcher, P. (2008). Gas Turbine Performance (second edition). Blackwell Science Ltd.

Wasserbauer C.A., and Glassman C.A. (1975). Fortran Program for predicting off-design performance of Radial-Inflow Turbines. NASA TN D-8063.

Watson, N. and Janota, M.S. (1982). Turbocharging the Internal Combustion Engine. McMillan Ltd., doi:https://doi.org/10.1007/978-1-349-04024-7

Watson, N. and Marzouk, M. (1977). "A non-linear digital simulation for turbocharged diesel engines under transient conditions", SAE Technical Paper 770123, SAE, Warrendale, PA. 
Table 1. Diesel engine technical specifications

\begin{tabular}{lccc}
\hline Cycle & 4 & Fuel LHV [kJ $/ \mathrm{kg}]$ & 42700 \\
Cylinders & 5 & Number of turbochargers & 1 \\
Bore[mm] & 200 & Injection timing & 10 degCA BTDC \\
Stroke[mm] & 300 & Injection pressure & $294 \mathrm{bar}$ \\
Fuel Type & Diesel & Number of injector nozzle holes & 8 \\
\hline
\end{tabular}


Table 2. Diesel engine shop trials data

\begin{tabular}{llllllllll}
\hline $\begin{array}{c}\text { Load } \\
{[\%]}\end{array}$ & $\begin{array}{c}\text { Output } \\
{[\mathrm{kW}]}\end{array}$ & $\begin{array}{c}\text { Fuel }^{*} \\
{[\mathrm{~kg} / \mathrm{h}]}\end{array}$ & $\begin{array}{c}\text { C.P } \\
{[\mathrm{barg}]}\end{array}$ & $\begin{array}{c}\text { C.T } \\
{[\mathrm{C}]}\end{array}$ & $\begin{array}{c}P_{a m b} \\
{[\mathrm{mbar}]}\end{array}$ & $\begin{array}{c}T_{a m b} \\
{[\mathrm{C}]}\end{array}$ & $\begin{array}{c}\text { RH } \\
{[\%]}\end{array}$ & $\begin{array}{c}P_{\max } \\
{[\mathrm{bar}]}\end{array}$ & $\begin{array}{c}T_{\text {exh }} \\
{[\mathrm{C}]}\end{array}$ \\
\hline 25 & 113 & 32.2 & 0.36 & 35 & 1001.5 & 31 & 62 & 62 & 283 \\
50 & 225 & 53.5 & 0.69 & 37 & 1003.7 & 30.5 & 66 & 83 & 339 \\
75 & 338 & 73.6 & 1.23 & 42 & 1003.5 & 31 & 65 & 108 & 365 \\
100 & 450 & 94.5 & 1.84 & 45 & 1003 & 31.5 & 59 & 131 & 399 \\
110 & 495 & 104.3 & 2.05 & 47 & 1002.7 & 32.5 & 54 & & \\
\hline
\end{tabular}


Table 3. Turbocharger fouling conditions

\begin{tabular}{ccccccc}
\hline & \multicolumn{3}{c}{ Centrifugal Compressor } & \multicolumn{3}{c}{ Radial Turbine } \\
\cline { 2 - 6 } $\begin{array}{c}\text { Fouling } \\
\text { condition }\end{array}$ & $\begin{array}{c}\text { Blade thick. } \\
\text { change[mm] }\end{array}$ & $\begin{array}{c}\text { Blade thick. } \\
\text { change [\%] }\end{array}$ & $\begin{array}{c}\text { Friction coef. } \\
\text { change [\%] }\end{array}$ & $\begin{array}{c}\text { Nozzle thick. } \\
\text { change [mm] }\end{array}$ & $\begin{array}{c}\text { Nozzle thick. } \\
\text { change [\%] }\end{array}$ & $\begin{array}{c}\text { Friction Coef. } \\
\text { change [\%] }\end{array}$ \\
\hline F1 & +0.2 & $+21 \%$ & $+13 \%$ & - & - & - \\
F2 & +0.5 & $+54 \%$ & $+50 \%$ & - & - & - \\
F3 & - & - & - & +0.5 & $-2.4 \%$ & $+37.5 \%$ \\
F1-F3 & +0.2 & $+21 \%$ & $+13 \%$ & +0.5 & $-2.4 \%$ & $+37.5 \%$ \\
F2-F3 & +0.5 & $+54 \%$ & $+50 \%$ & +0.5 & $-2.4 \%$ & $+37.5 \%$ \\
\hline
\end{tabular}


Table 4. System operation dependence on fouling

\begin{tabular}{|c|c|c|c|c|c|}
\hline \multirow[b]{2}{*}{$\begin{array}{l}\text { Fouling } \\
\text { condition }\end{array}$} & \multicolumn{5}{|c|}{ Specific shaft horse power $(377 \mathrm{~kW})$} \\
\hline & $\begin{array}{c}\mathrm{T} / \mathrm{C} \\
\text { rotational } \\
\text { speed }\end{array}$ & $\begin{array}{c}\text { Boost } \\
\text { Pressure }\end{array}$ & $\mathrm{T} 4$ & T5 & sfc \\
\hline $\mathrm{F} 1$ & $-0.9 \%$ & $-10.0 \%$ & $3 \%$ & $4 \%$ & $0.28 \%$ \\
\hline $\mathrm{F} 2$ & $-2.0 \%$ & $-22.2 \%$ & $8 \%$ & $12 \%$ & $1.06 \%$ \\
\hline F3 & $-2.2 \%$ & $-6.2 \%$ & $2 \%$ & $4 \%$ & $0.17 \%$ \\
\hline F1-F3 & $-2.6 \%$ & $-13.9 \%$ & $5 \%$ & $8 \%$ & $0.61 \%$ \\
\hline F2-F3 & $-3.7 \%$ & $-26.1 \%$ & $9 \%$ & $15 \%$ & $1.31 \%$ \\
\hline
\end{tabular}


Table 5. Fouled intercooler parameters

\begin{tabular}{llll}
\hline Condition & sfc $[\mathrm{g} / \mathrm{kWh}]$ & $\mathrm{T} 4\left({ }^{\circ} \mathrm{C}\right)$ & $\mathrm{T} 5\left({ }^{\circ} \mathrm{C}\right)$ \\
\hline Healthy & 214.49 & 480 & 360 \\
Fouled Intercooler & $216.72(+1.04 \%)$ & $497(+17)$ & $381(+21)$ \\
\hline
\end{tabular}




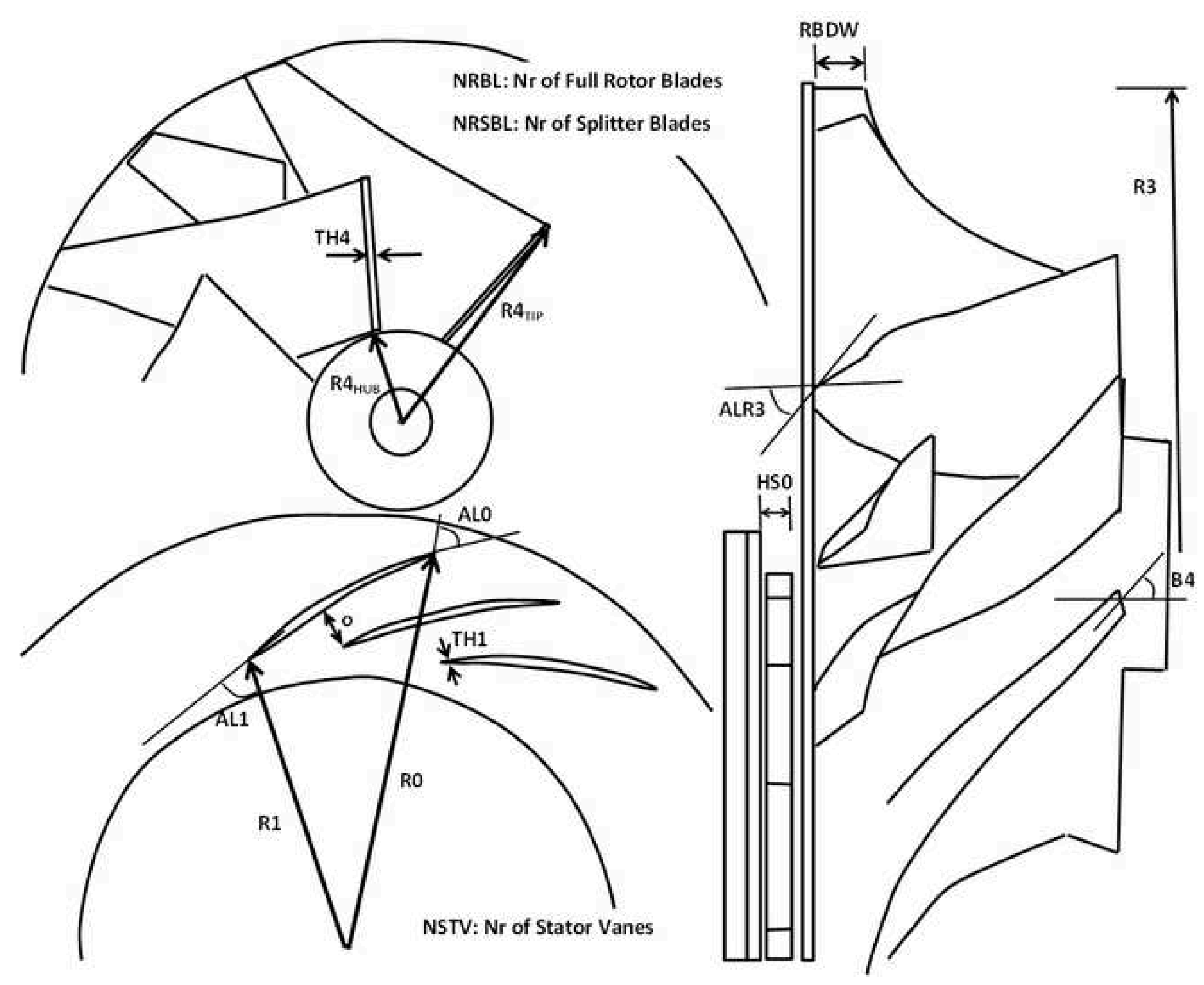




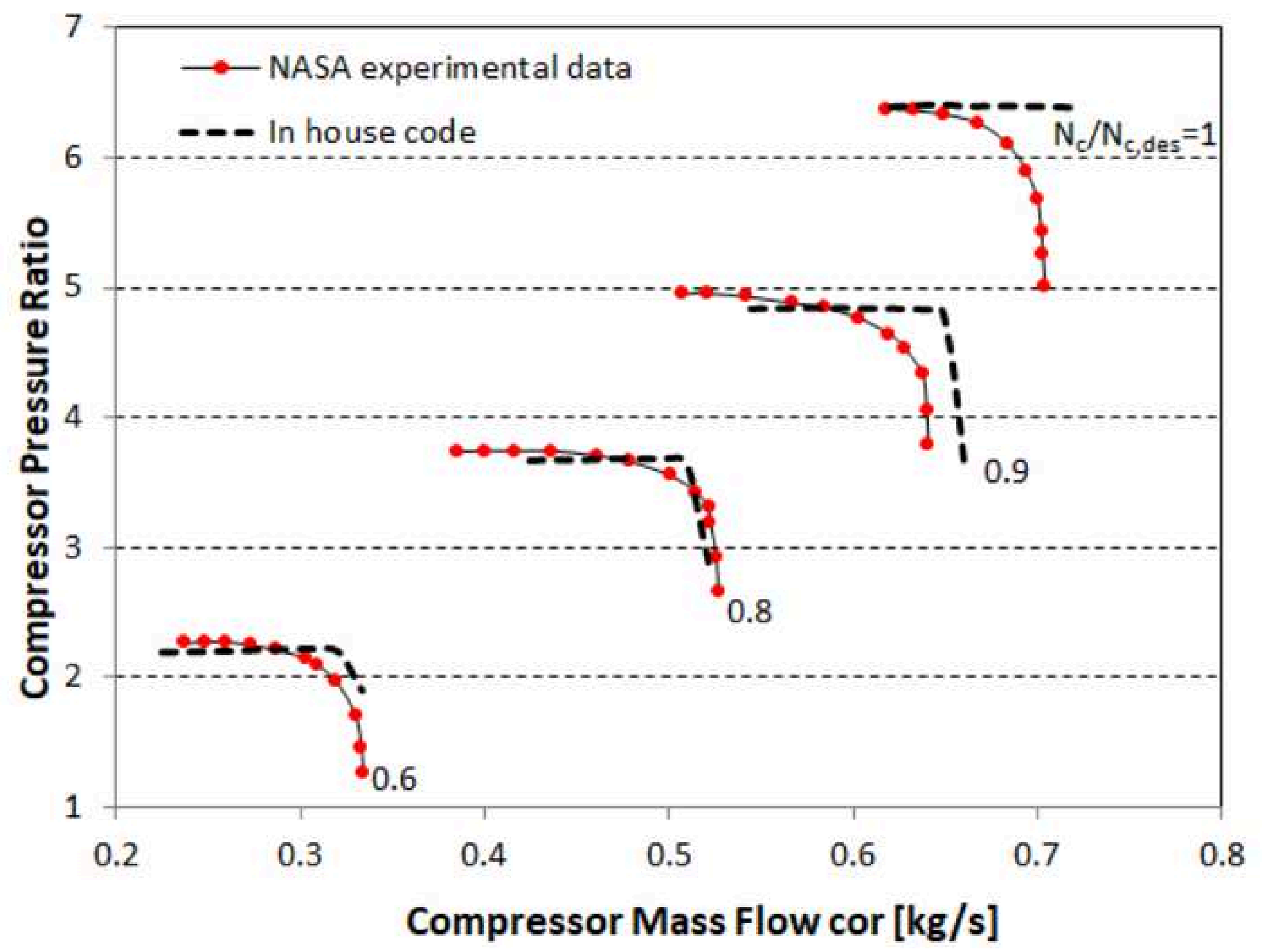

Compressor Mass Flow cor [kg/s] 


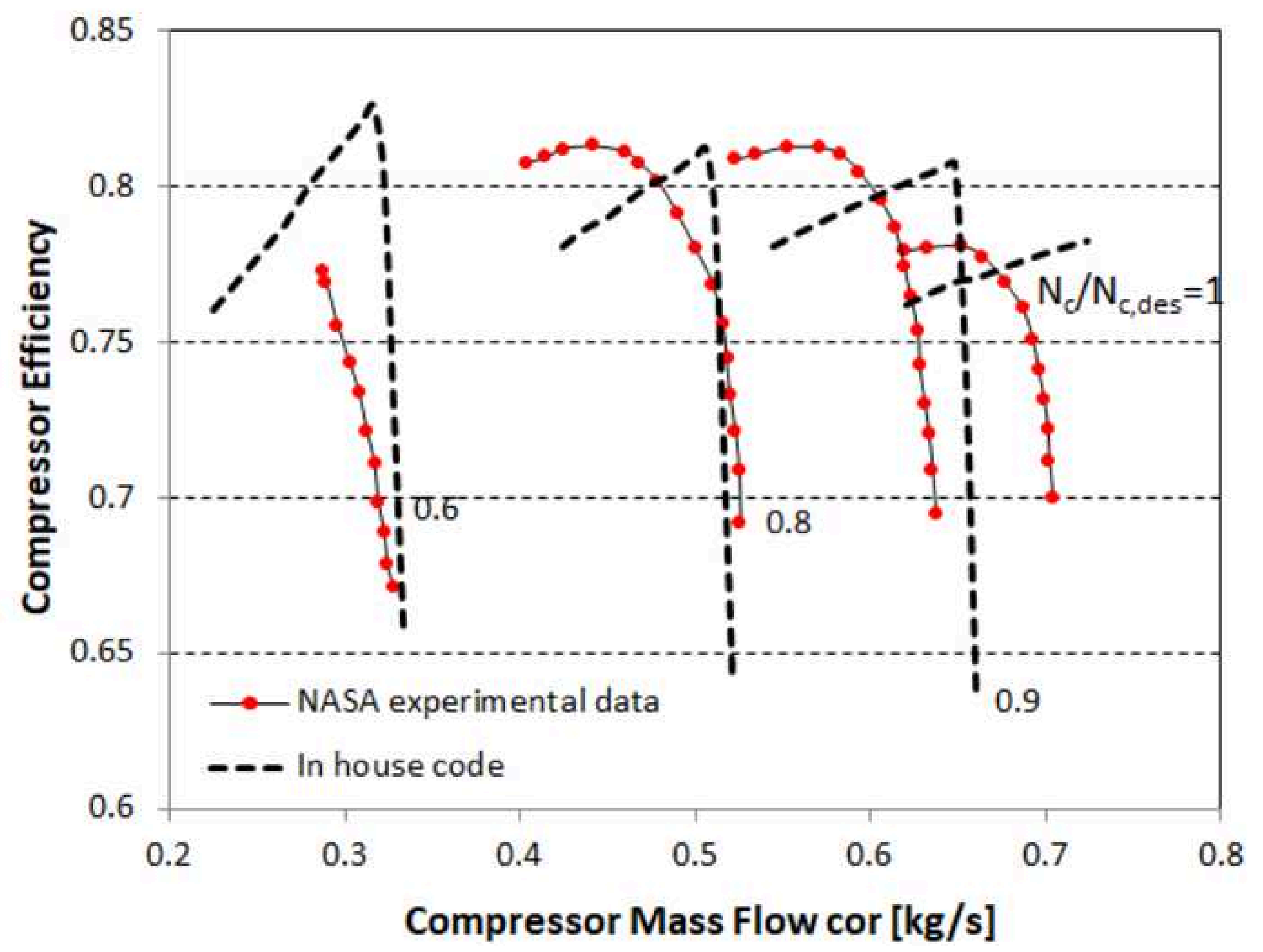




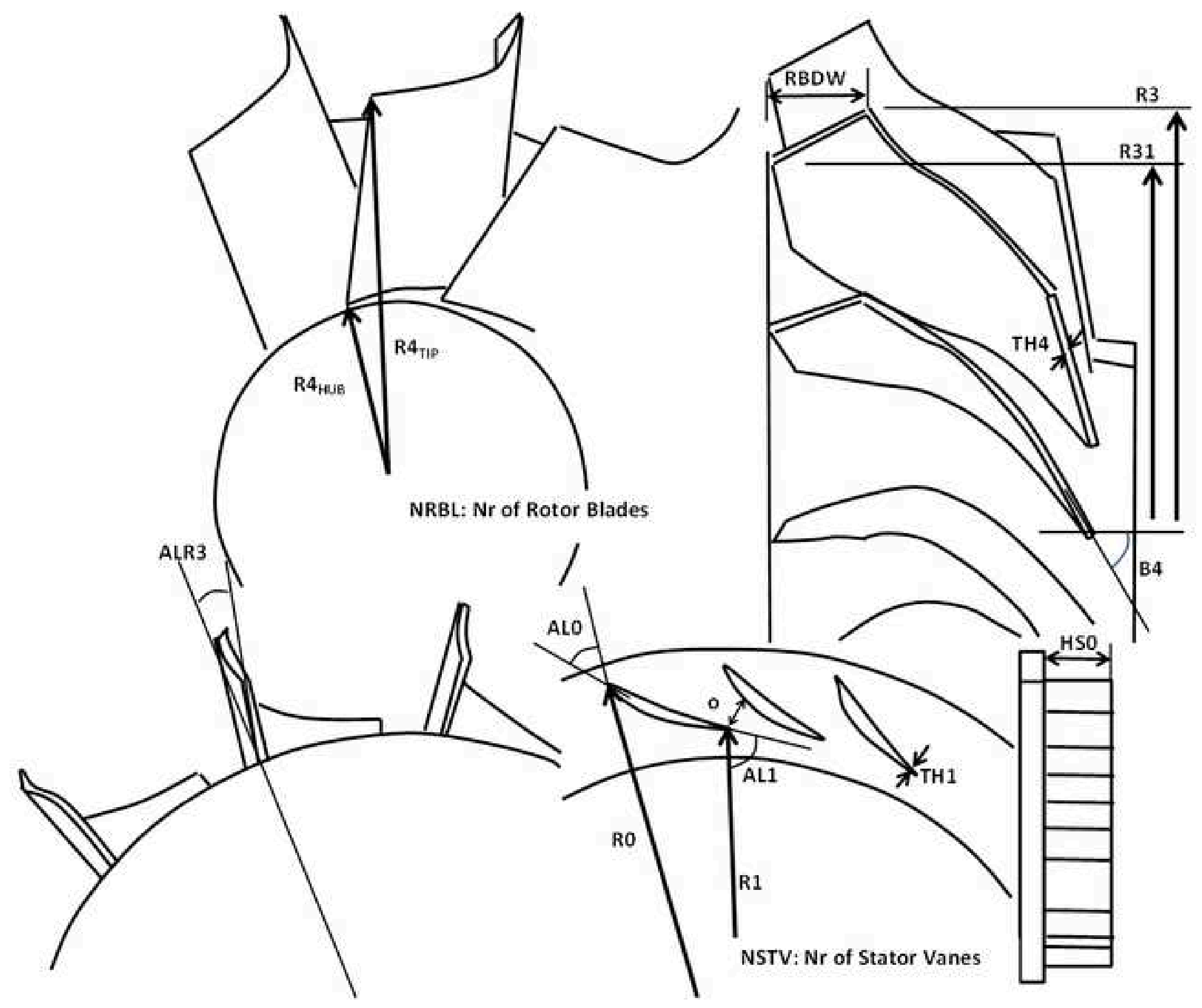




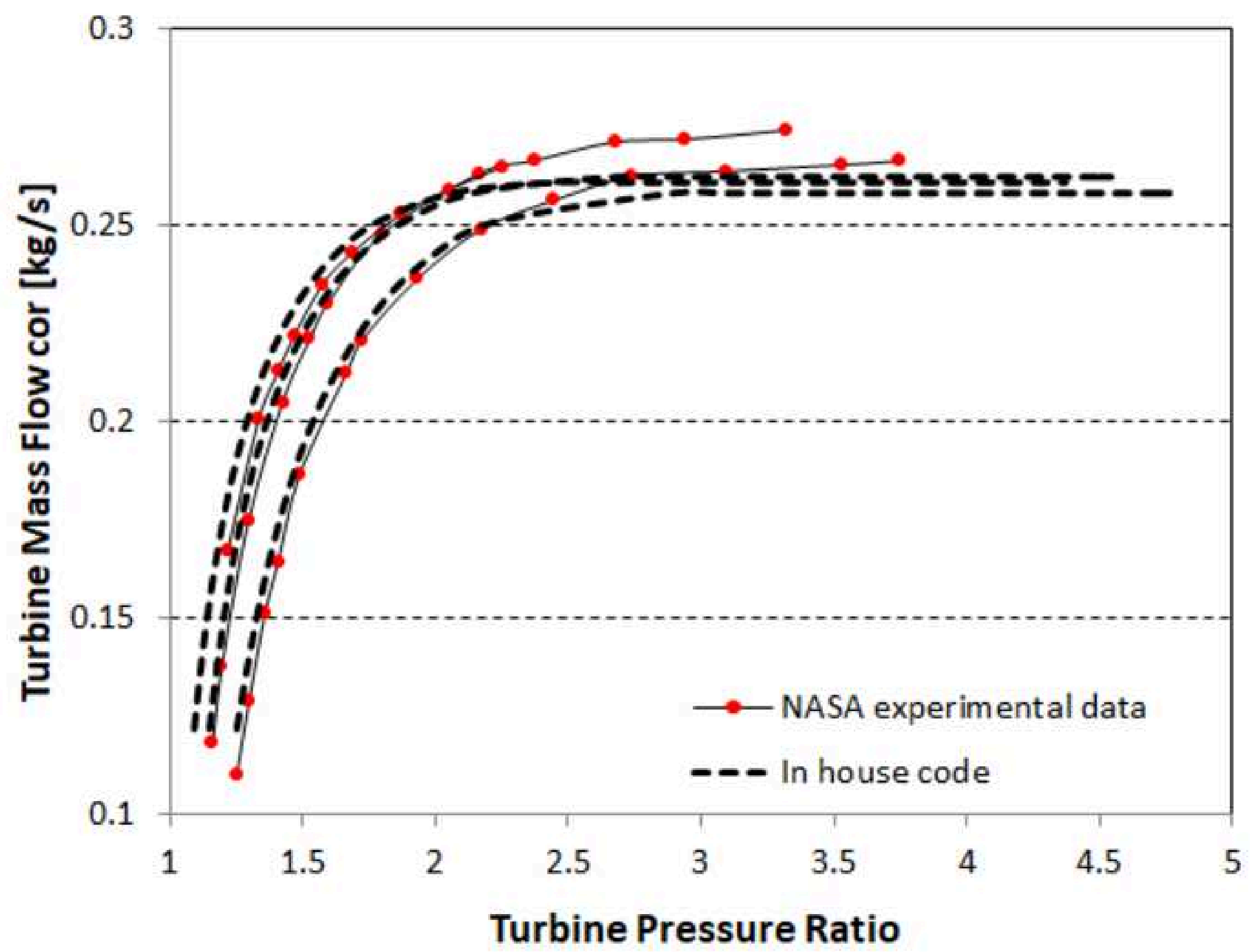




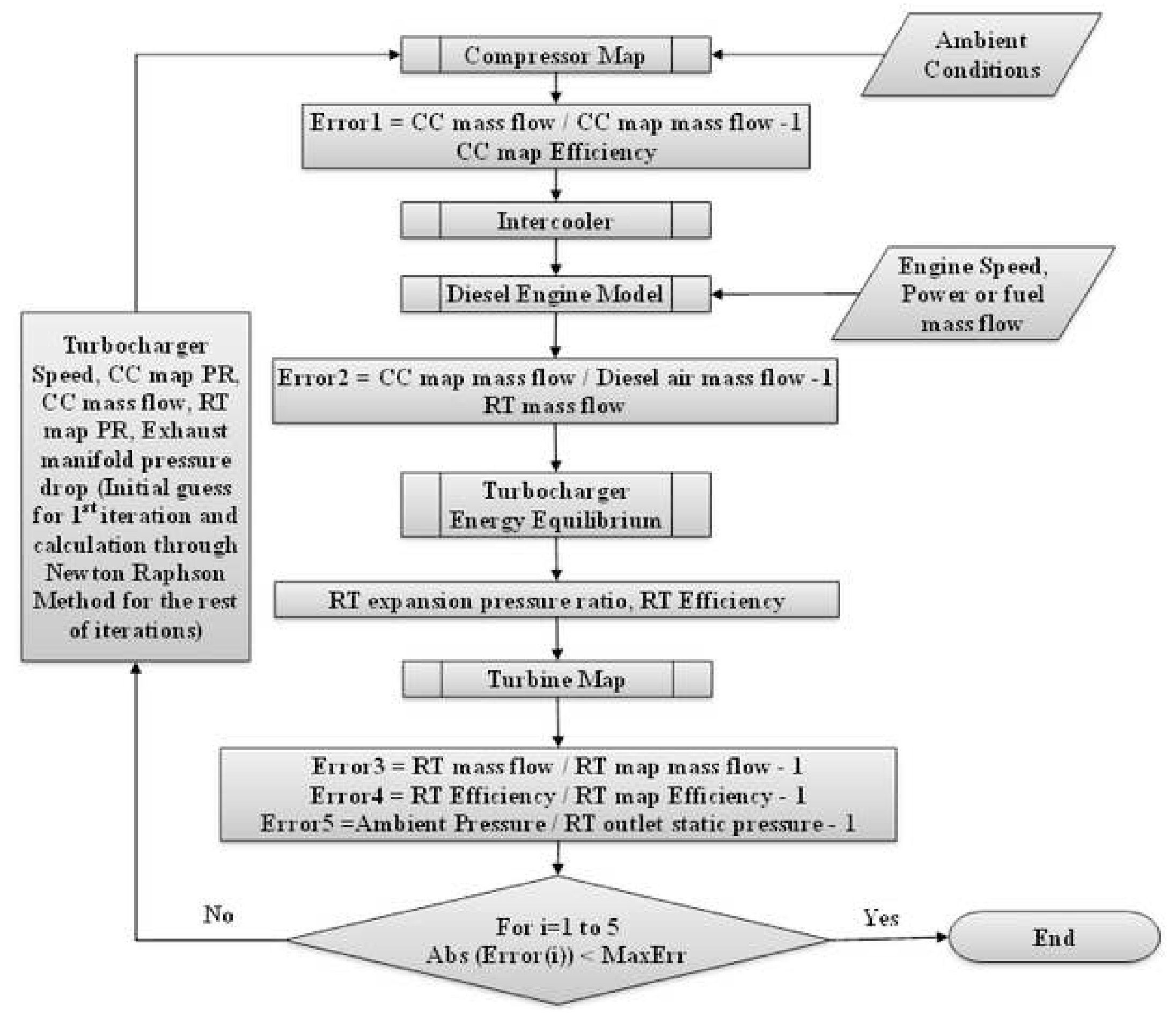

\section{Turbocharger} Speed, CC map PR CC mass flow, RT map PR, Exhaust manifold pressure drop (Initial guess for $1^{\text {st }}$ iter ation and calculation through Newton Raphson Method for the rest of iter ations)

Error $3=$ RT mass flow $/$ RT map mass flow -1

Error 4 = RT Efficiency $/$ RT map Efficiency -1

Error $5=$ Ambient Pressure $/$ RT outlet static pressure -1

No

$$
\text { For } \mathrm{i}=1 \text { to } 5
$$

Error 2 $=\mathrm{CC}$ map mass flow $/$ Diesel air mass flow -1

$$
\text { RT mass flow }
$$



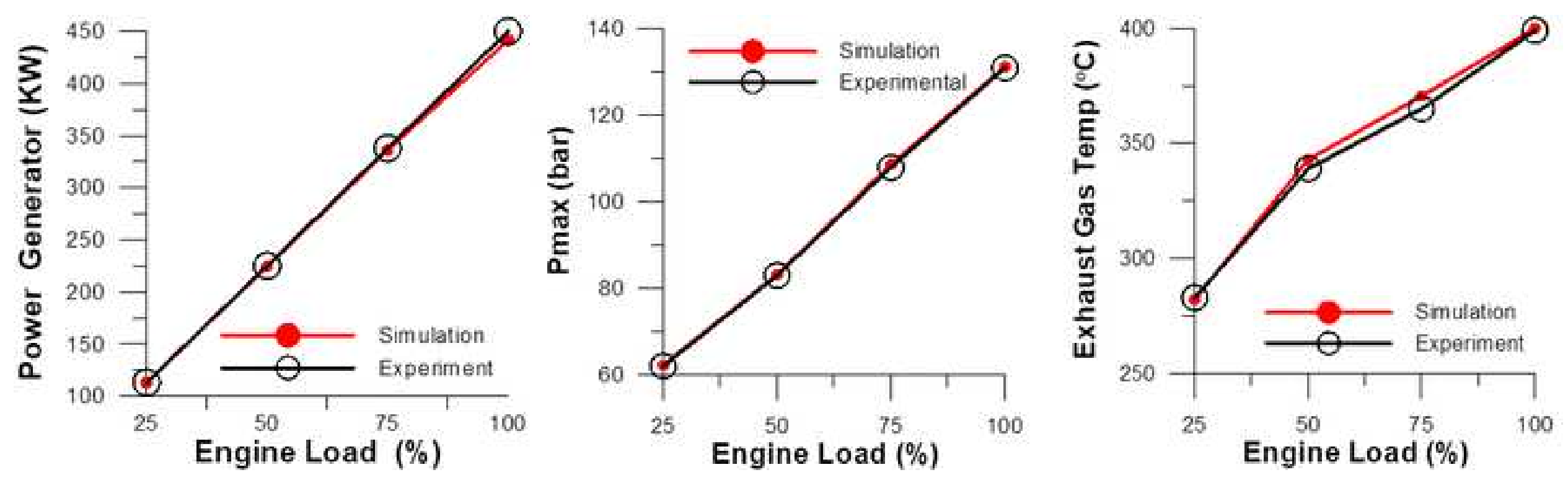


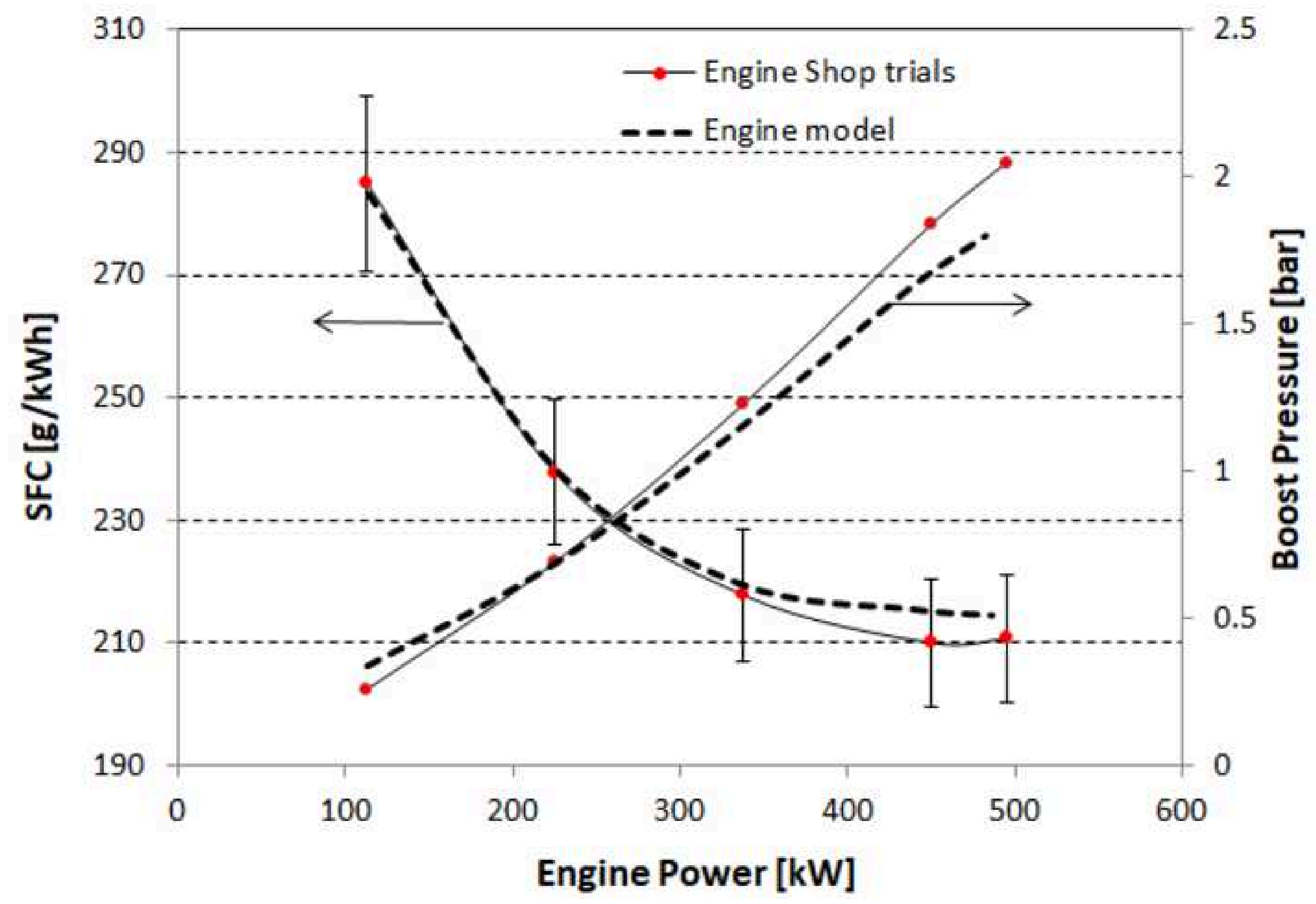




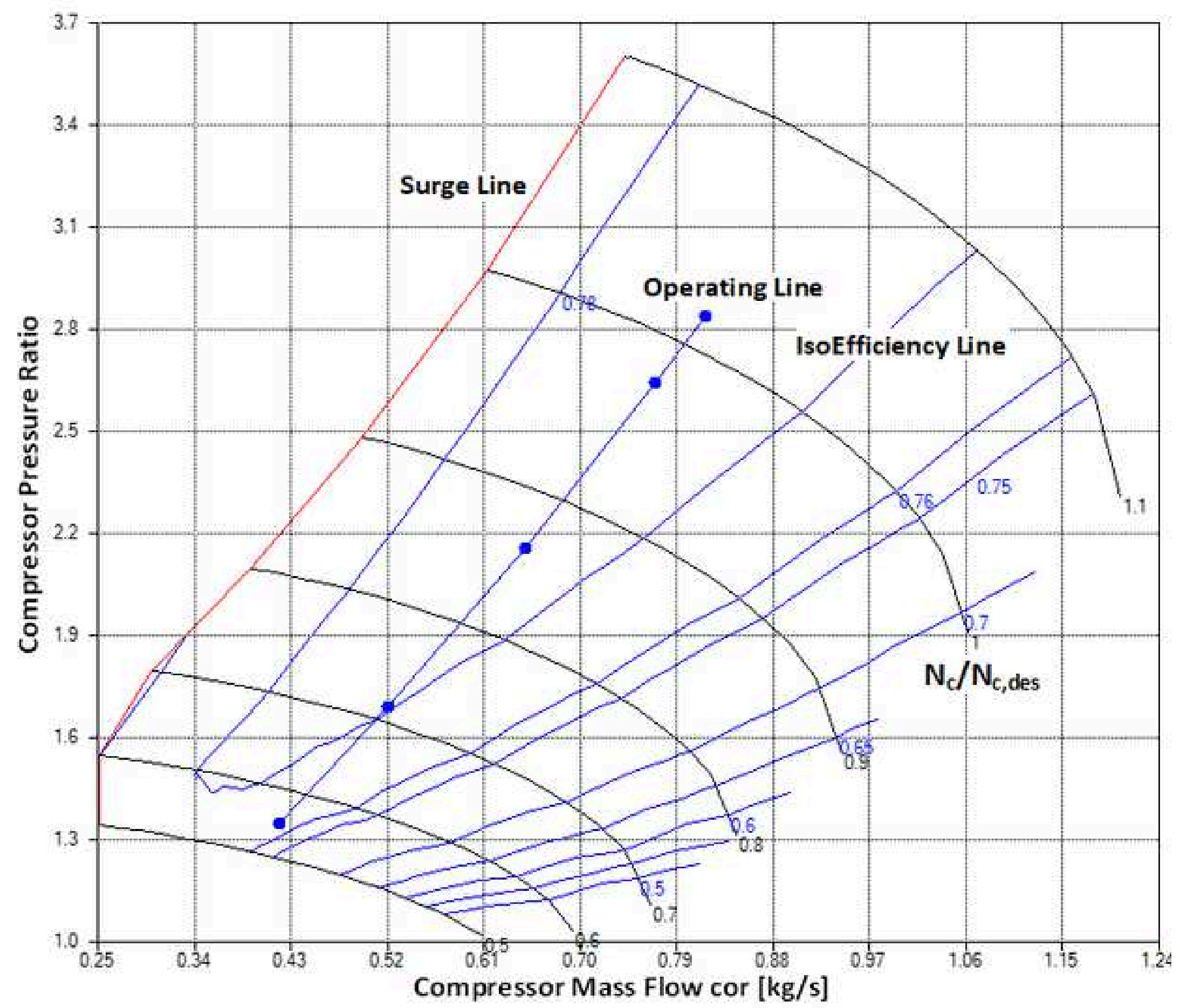




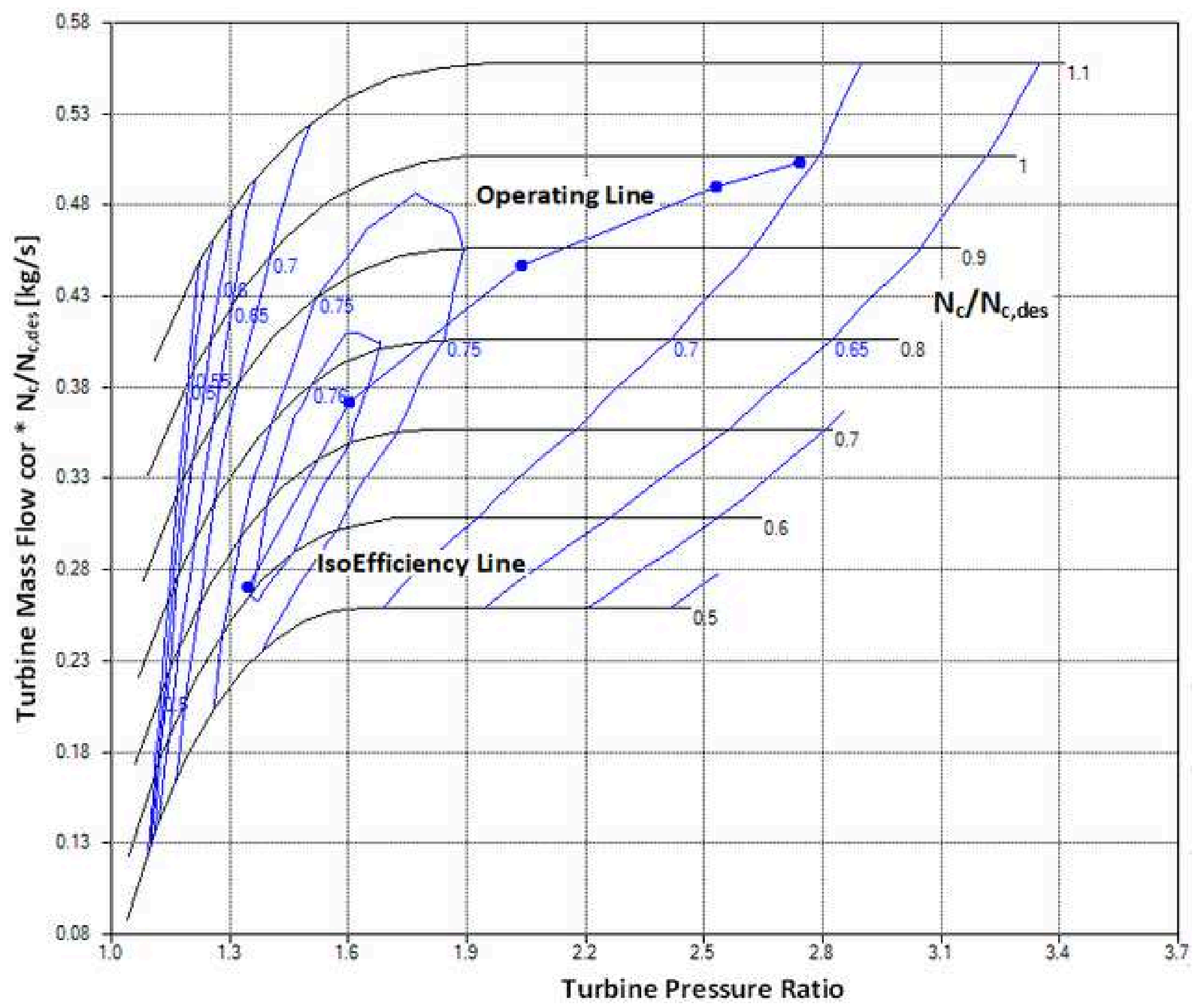




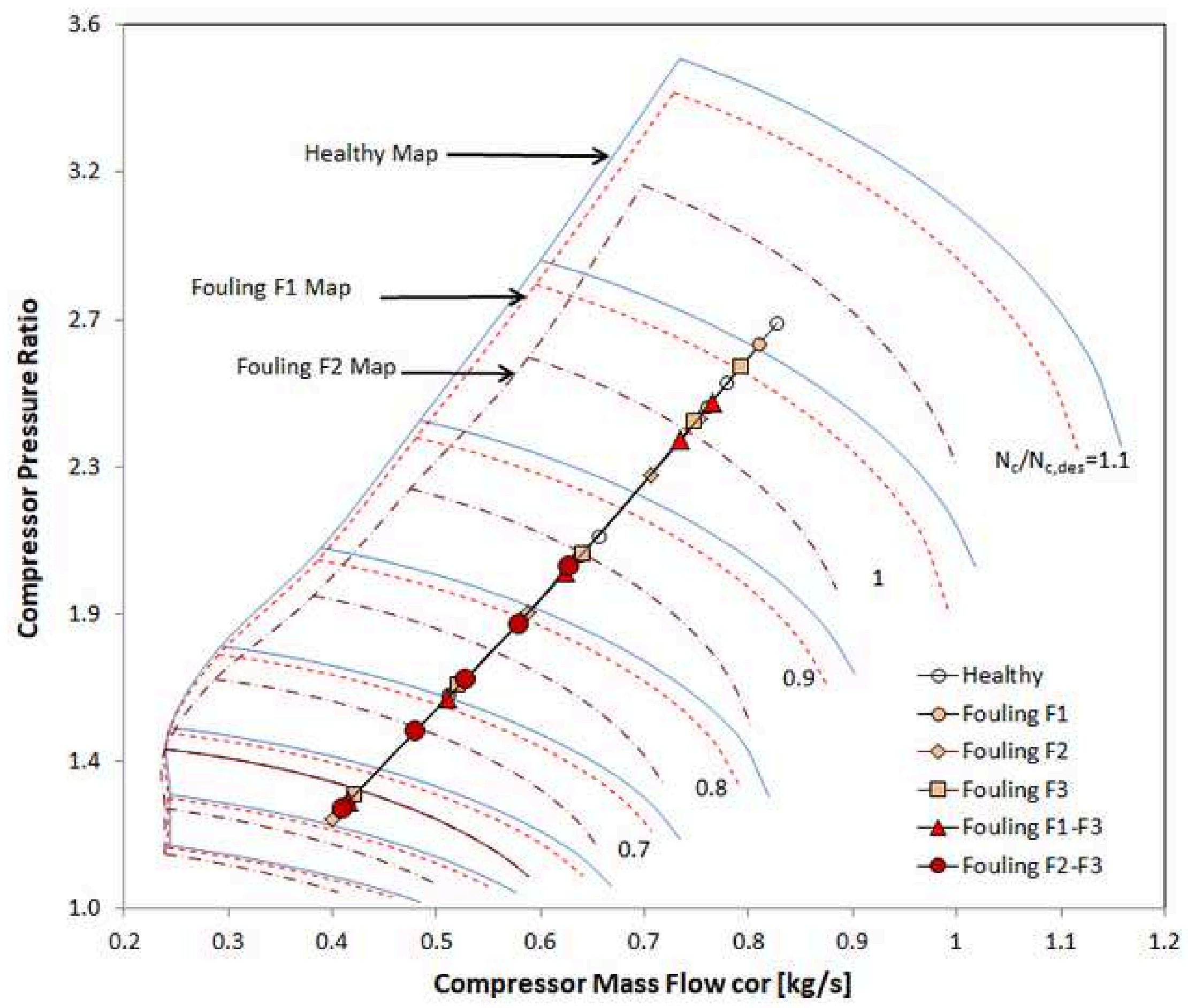




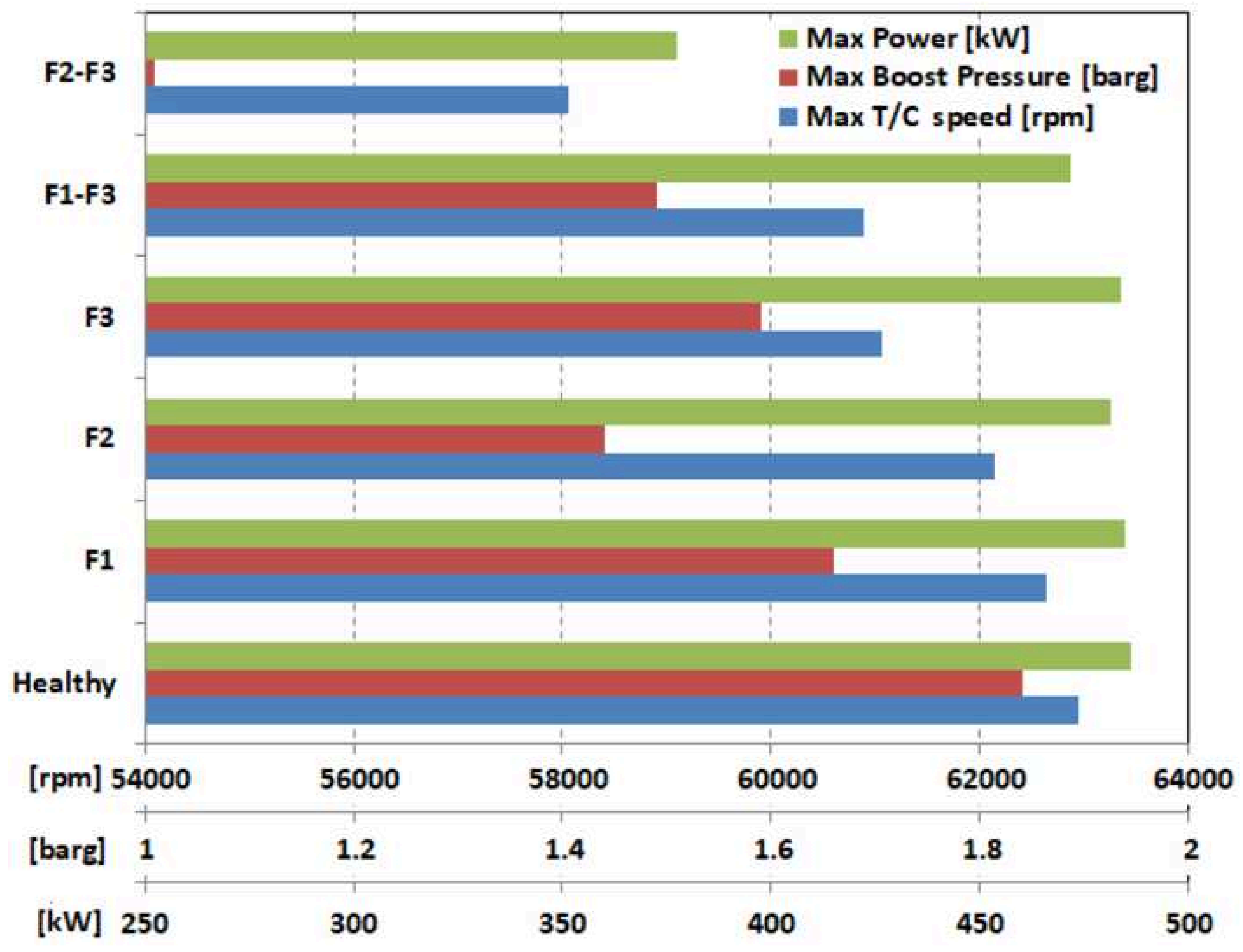




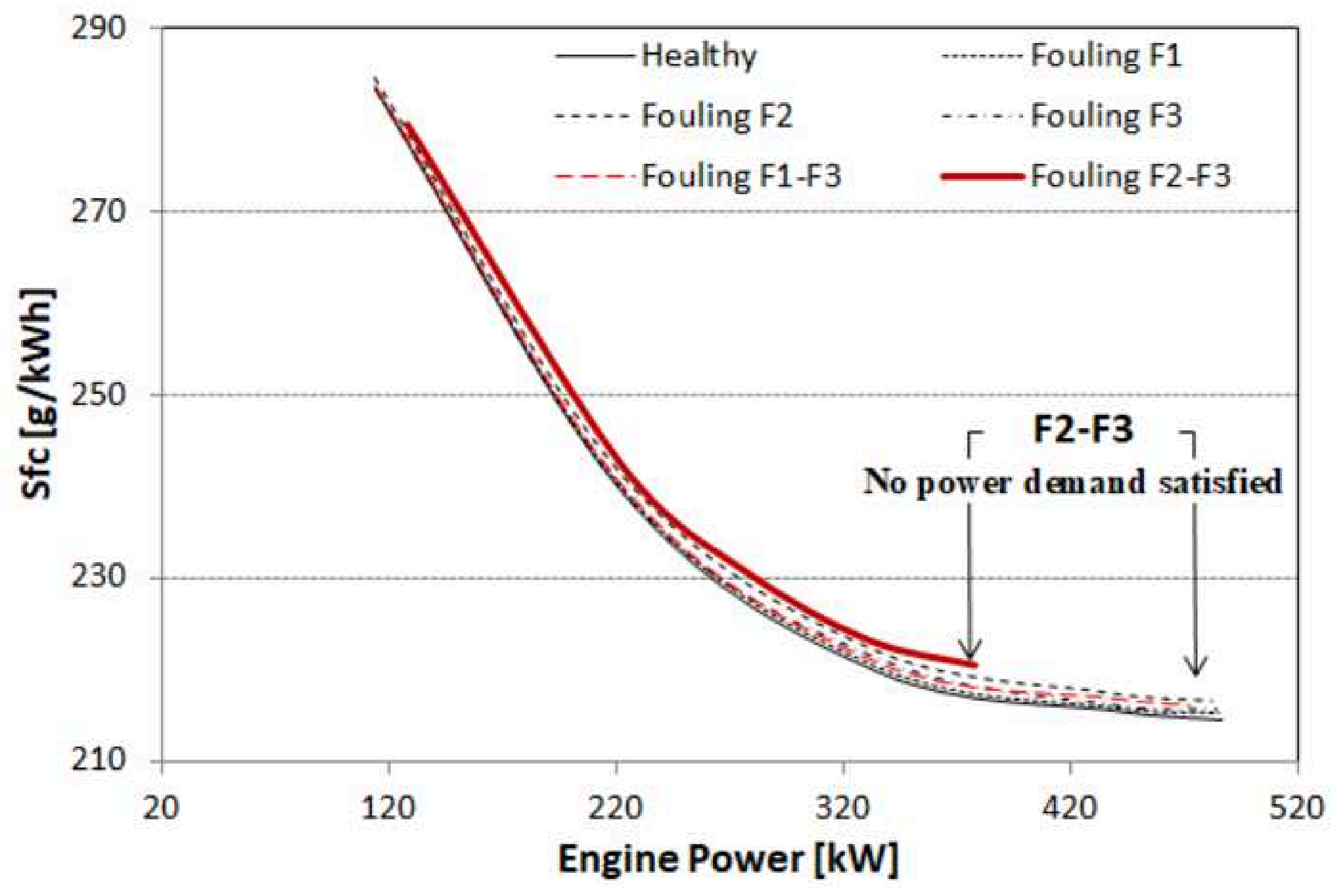




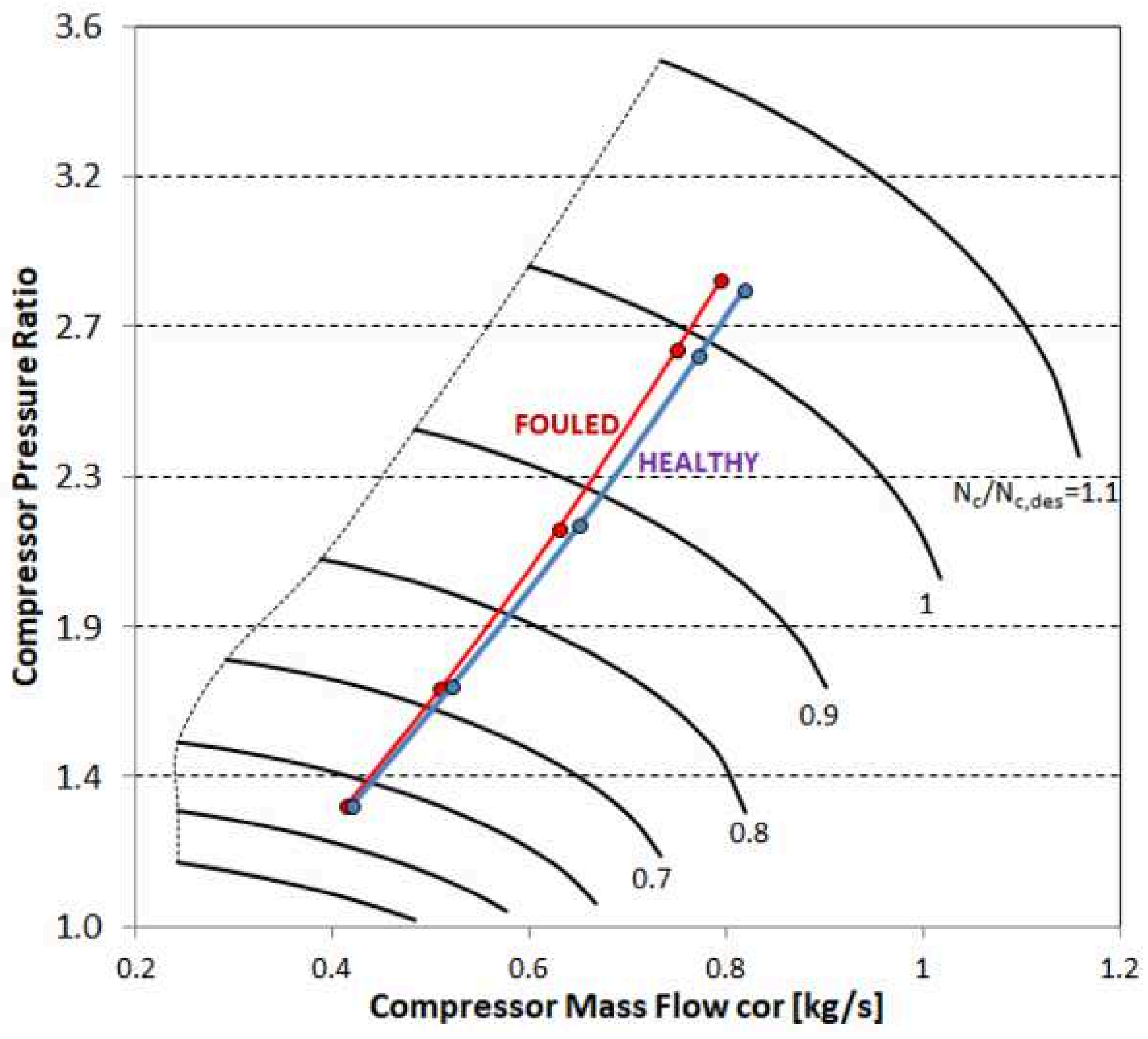




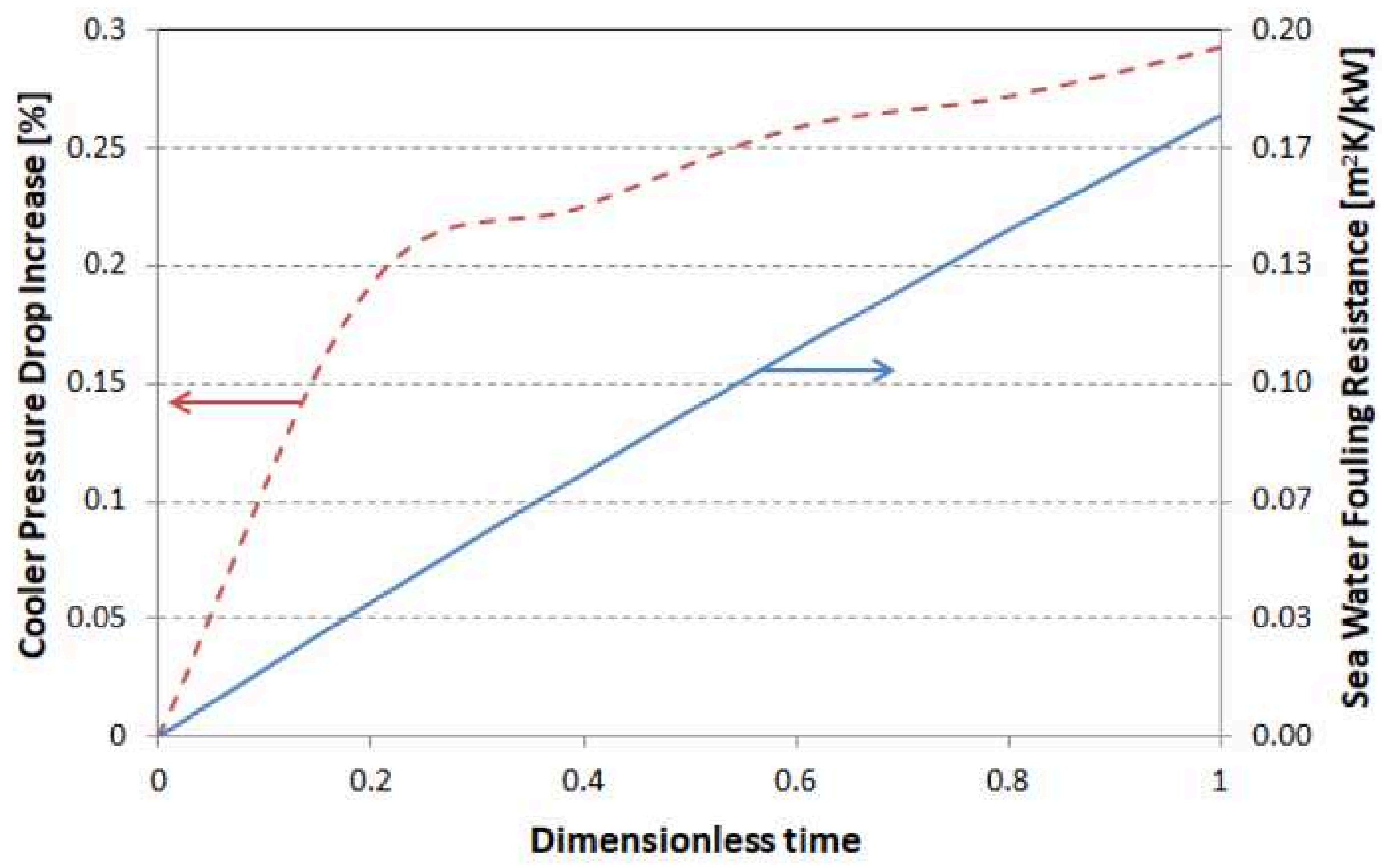




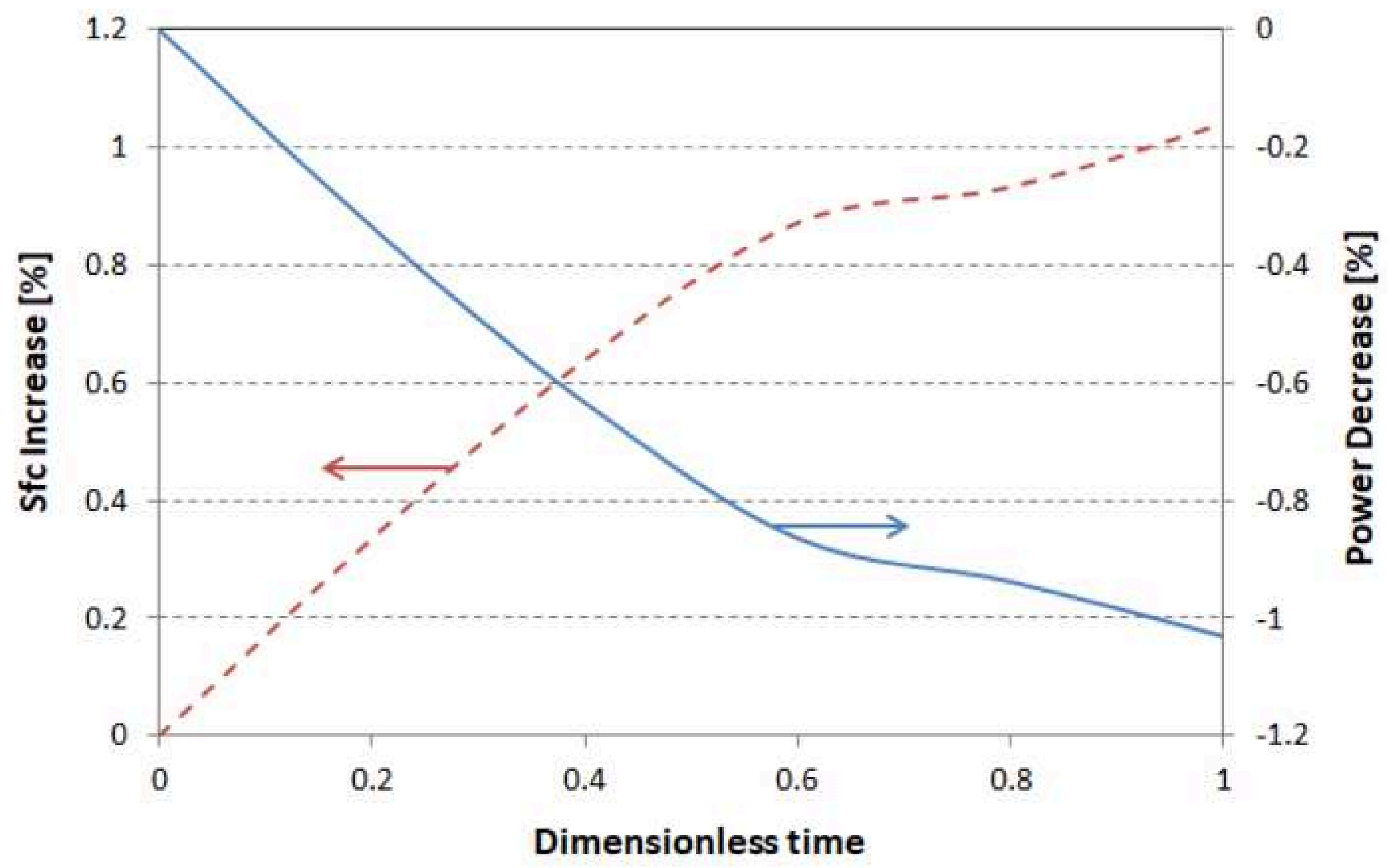




\section{$1 \quad$ List of Figures}

2 1. Fig. 1. Centrifugal compressor geometry specifications

3 2. Fig. 2. In house CC code validation with NASA experimental data (total pressure ratio)

4 3. Fig. 3. In house CC code validation with NASA experimental data (efficiency)

5 4. Fig. 4. Radial turbine geometry specifications.

6 5. Fig. 5. In house RT code validation with NASA experimental data

$7 \quad 6$. Fig. 6. Coupling between T/C and diesel engine model

8 7. Fig. 7. Comparison between calculated and measured values used for model calibration.

9 8. Fig. 8. Comparison between calculated and measured Sfc and boost pressure

109 9. Fig. 9. Healthy compressor map and operating line

11 10. Fig. 10. Healthy turbine map and operating line

12 11. Fig. 11. Compressor map and operating line change due to fouling

13 12. Fig. 12. Engine power, boost pressure and T/C speed variation due to fouling

14 13. Fig. 13. sfc variation due to fouling

15 14. Fig. 14. Operating line movement due to intercooler fouling

16 15. Fig. 15. Intercooler fouling pressure drop and resistance against time

17 16. Fig. 16. Sfc and power change rate due to fouling 


\title{
Integrated simulation framework for assessing turbocharger fault effects on diesel-engine performance and operability
}

\author{
Ntonas, Konstantinos
}

ASCE

Ntonas K, Aretakis N, Roumeliotis I, et al., (2020) Integrated simulation framework for assessing turbocharger fault effects on diesel-engine performance and operability. Journal of Energy

Engineering, Volume 46, Issue 4, August 2020, Article number 04020023

https://doi.org/10.1061/(ASCE)EY.1943-7897.0000673

Downloaded from Cranfield Library Services E-Repository 